

\section{DISCLAIMER}

This report was prepared as an account of work sponsored by an agency of the United States Government. Neither the United States Government nor any agency Thereof, nor any of their employees, makes any warranty, express or implied, or assumes any legal liability or responsibility for the accuracy, completeness, or usefulness of any information, apparatus, product, or process disclosed, or represents that its use would not infringe privately owned rights. Reference herein to any specific commercial product, process, or service by trade name, trademark, manufacturer, or otherwise does not necessarily constitute or imply its endorsement, recommendation, or favoring by the United States Government or any agency thereof. The views and opinions of authors expressed herein do not necessarily state or reflect those of the United States Government or any agency thereof. 


\section{DISCLAIMER}

Portions of this document may be illegible in electronic image products. Images are produced from the best available original document. 


\section{BLAST-NDUCED TRANSLATIONAL EFFECTS}

E. Royce Fletcher

I. Gerald Bowen

Technical Progress Report

on

Contract No. DA-49-146-XZ-372

This work, an aspect of investigations dealing with the Biological Effects of Blast from Bombs, was supported by the Defense Atomic Support Agency of the Department of Defense.

(Reproduction in whole or in part is permitted for any purpose of the United States Government. )

Lovelace Foundation for Medical Education and Research

Albuquerque, New Mexico 


\section{FOREWORD}

This report describes experimental and theoretical studies of blast-induced translational effects with regard to dummies, animals, stones, concrete building blocks, and spheres. Some results are presented of mathematical model studies of the accelerative as well as the decelerative phase of displacement. The present siudy represents a further analysis of previously reported data and is intended to clarify some of the problems associated with translation. The biological implications of translational events are not discussed in this paper.

This report and some additional material were summarized on October 6, 1966, before a symposium on the Biological Effects of Air Blast at the National Academy of Sciences sponsored by the NAS-NRC Committee on Hearing, Bioacoustics, and Biomechanics, "CHABA." On October 13, 1966, the report was presented at the New York Academy of Sciences conference on Prevention of and Protection against Accidental Explosion of Munitions. The text was also submitted for inclusion in the Annals of the New York Academy of Sciences. 

The authors wish to acknowledge their appreciation as follows: to Clayton $\mathrm{S}$. White for many informative discussions and for editorial assistance in preparing the final manuscript; to Robert F. D. Perett and Walter A. Scheurle for their assistance in gathering and analyzing the data; to Mildred G. Elrick and Ray. W. Albright for developing some of the computer programs used in this report; to Robert A. Smith and Joyce Blaine for preparing all the illustrative material; to Mildred E. Blake for editorial support; to Lee Sanders and Laura M. Carrasco for editorial and secretarial assistance; and finally to the Defense Atomic Support Agency of the Department of Defense for contract support. 


\title{
BLAST-INDUCED TRANSLATIONAL EFFECTS
}

\author{
E. Royce Fletcher and I. Gerald Bowen
}

\section{INTRODUCTION}

The Lovelace Foundation has conducted experiments on two operations at the Nevada Test Site (Bowen et al., 1956, 1963; Taborelli et al., 1959) and on two operations using chemical explosives (Bowen et al., 1965; Fletcher et al., 1965a; Bowen and Fletcher, unpublished) in order to evaluate the translational effects produced by the blast waves from nuclear and conventional explosions. Experiments were performed on five nuclear shots ranging in yield from 11 to $44 \mathrm{kt}$ and on two high explosive (HE) shots having yields of 50 and 500 tons. Translational velocities and in some cases total displacements were determined for about 20,000 objects, such as spheres, animals, anthropomorphic dummies, stones, concrete building blocks, window-glass fragments, and steel fragments.

Theoretical studies and laboratory experiments (Bowen et al., 1961, 1962; Fletcher etal., 1961; Fletcher et al., unpublished) were done to help explain the mechanisms involved in the translation of objects by blast waves and thus to make it possible to predict their behavior when exposed to any specified arbitrary blast wave. The decelerative phase of displacement when the objects come to rest by sliding, rolling, and bouncing along the ground has also been studied both theoretically and experimentally (Fletcher, .1965b).

In the present paper the results of several experiments (mostly conducted during a 500-ton TNT shot) involving the translation of spheres, animals, dummies, stones, and blocks will be described. Theoretical time-displacement histories for the translated objects were computed using a revised mathematical model of blast-induced translation (Fletcher et al., unpublished). These calculations were based on blast waves predicted by various authors as well as on experimentally determined blast waves; in this way, the various predictions can be compared not only to experiment, but also to each other.

\section{TRANSLATION MODEL}

The revised mathematical model (Fletcher et al., unpublished) of blast-induced translational effects is similar to the earlier models (Bowen et al., 1961, 1962), but two major features have been added: (1) arbitrary blast-wave forms can be used and (2) the effects of ground friction can be included if the translating object is tumbling over smooth, flat ground. In the earlier models it was assumed that the blast waves 
were classical in form and that the objects did not strike anything while they were being translated. Thus the total displacement of a translated object could not be computed since these models included no way of describing the motion of the object during decelerative tumbling along the ground.

As in the case of the earlier models, time-displacement histories are calculated with the aid of a digital-computer program based on the mathematical model. This program will accept an overpressure wave and either a dynamic-pressure wave or a wind-velocity curve, and will generate the time-displacement history of an object (whose acceleration coefficient " may vary with time) which may either be assumed to be in free air or to be bouncing and sliding along the ground as it translates. If an equation is not available for the blast wave, a "broken-line" approximation may be used and in this way precursor and other nonclassical wave forms can be handled.

The effects of ground friction on the object are approximated in the model by an average decelerative force which is assumed to act on the object throughout the entire motion. The value of this average decelerative force due to ground friction was derived from empirical fits to data obtained by dropping animals, stones, and concrete blocks from a truck traveling at various speeds and measuring the total displacements. The force per unit mass (i.e., the deceleration) was found to be a function of velocity and mass for animals and a function of velocity only for stones and concrete blocks. Equations for the frictional deceleration will be presented in the next section along with a description of the "calibration" experiments from which they were derived.

In developing the model, a differential equation was derived which describes the motion of an object acted upon by blast winds and ground friction. Since this equation could not be solved explicitly, a linear approximation to the solution over finite time steps small enough to introduce negligible errors in the final answers was used in the computer program. The computed acceleration, velocity, and displacement of the object, as well as the pertinent blast-wave parameters, are plotted and printed out at any specified interval of time.

\section{CALIBRA TION EXPERIMENTS}

In order to use the translation model to predict the complete timedisplacement histories of objects bouncing along the ground; it was necessary to include the effects of ground friction in the model in some way. Therefore, experiments to study ground friction (Fletcher, 1965b) were performed in which more than 500 objects were dropped on smooth flat ground (a graded airstrip on an alluvial plain) from a truck traveling at speeds ranging from 10 to $60 \mathrm{mph}$. Total displacements of the objects were recorded as well as the distances between individual impacts if the imprints could be located. The experimental objects included stones

*Defined as the area presented to the wind multiplied by the drag coefficient and divided by the mass. 
$(1.3-116 \mathrm{lb})$, ordinary concrete building blocks $(25.0-32.5 \mathrm{lb})$, concrete-filled building blocks $(55.0-56.5 \mathrm{lb})$, guinea pigs $(1.2-1.7 \mathrm{lb})$, rabbits $(5.2-8.1 \mathrm{lb})$, dogs $(38.0-44.6 \mathrm{lb})$, and a goat $(59 \mathrm{lb})$. The concrete building blocks ( $7.5 \times 7.5 \times 15.5$ inches) and the animals, which had been sacrificed by injections of Nembutal, were dropped in various orientations to determine variations in the subsequent motion.

The animal displacements showed no variation with orientation ${ }^{*}$ but did show a significant variation with mass; for a given speed the larger animals required a slightly longer distance to stop than did the smaller ones. A dimensional analysis approach was used in an attempt to scale from one animal to another and thus to explain the variation in total displacement with mass. It was assumed that the total displacement of the animals, S, was only a function of: (1) the initial velocity, $Z_{0}$; (2) the acceleration of gravity, g; (3) the mass of the animal, $m$; (4) the average density of the animal, $p$; (5) the coefficient of sliding friction, $\mu_{s}$; and (6) the coefficient of rolling friction, $\mu_{r}$. Then,by applying the principles of dimensional analysis and assuming that $g$, $\rho$, and $\mu_{s}$ are constant for all the animal drops, the following relation was derived:

$$
\mathrm{S} / \mathrm{m}^{1 / 3}=\mathrm{f}\left(\dot{\mathrm{Z}}_{\mathrm{o}} / \mathrm{m}^{1 / 6}, \mu_{\mathrm{r}} / \mathrm{m}^{1 / 3}\right) \text {. }
$$

It should be noted that dimensional analysis cannot predict the nature of the undetermined function, $f$. Therefore, in an attempt to determine $f$ empirically, a plot was made of $\mathrm{S} / \mathrm{m} 1 / 3$ vs $\mathrm{Z}_{0} / \mathrm{m} 1 / 6$. On this plot, the datum points for all four species fell along a single curve (a separate curve was needed for each species on a plot of $S$ vs $\dot{Z} \mathcal{d}$ indicating that, within experimental accuracy, $\mathrm{s} / \mathrm{m}^{1 / 3}$ is only a function of $\dot{z}_{\mathrm{o}} / \mathrm{m} / \mathrm{m}$ and not a function of $\mu_{r} / \mathrm{m}^{1 / 3}$. This could be interpreted in either of two ways: (1) $\mu_{r} / \mathrm{m}^{1} / 3^{r}$ is a constant or, at least if it varies, the effect on $S$ was too small to measure in the calibration experiments, or (2) $\mu_{r}$ should not have been included in the list of parameters of which $S$ is assumed to be a function. It was further noted that when the plot of $\mathrm{s} / \mathrm{m} 1 / 3 \mathrm{vs} \dot{\mathrm{Z}} \mathrm{d} / \mathrm{m} / 6$ was made on log-log paper, the single curve appeared to be a straight line.

In view of the above considerations, it was decided to analyze the animal data in the form

$$
\log _{10}\left[\mathrm{~S}(165 / \mathrm{m})^{1 / 3}\right]=A+B \log _{10}\left[\dot{Z}_{0}(165 / \mathrm{m})^{1 / 6}\right]
$$

where $A$ and $B$ are constants and $165 / \mathrm{m}$ is used instead of $1 / \mathrm{m}$ so that the chart prepared to show this relation, EIGURE 1, can be read directly as $S$ vs $\dot{Z}_{O}$ for a 165-1b animal. For an animal of any other mass, some calculation would be involved to obtain $S$ as a function of $\dot{Z}_{0}$ from the chart. From the 230 datum points in FIGURE 1, it can be seen that the results for all four species are in good agreement, and that the scatter is quite low, the standard error of estimate in $\mathrm{S} / \mathrm{m}^{1 / 3}$ being approximately 11 percent.

* Regardless of the original orientation, the animal assumed a rolling position about its long axis. 


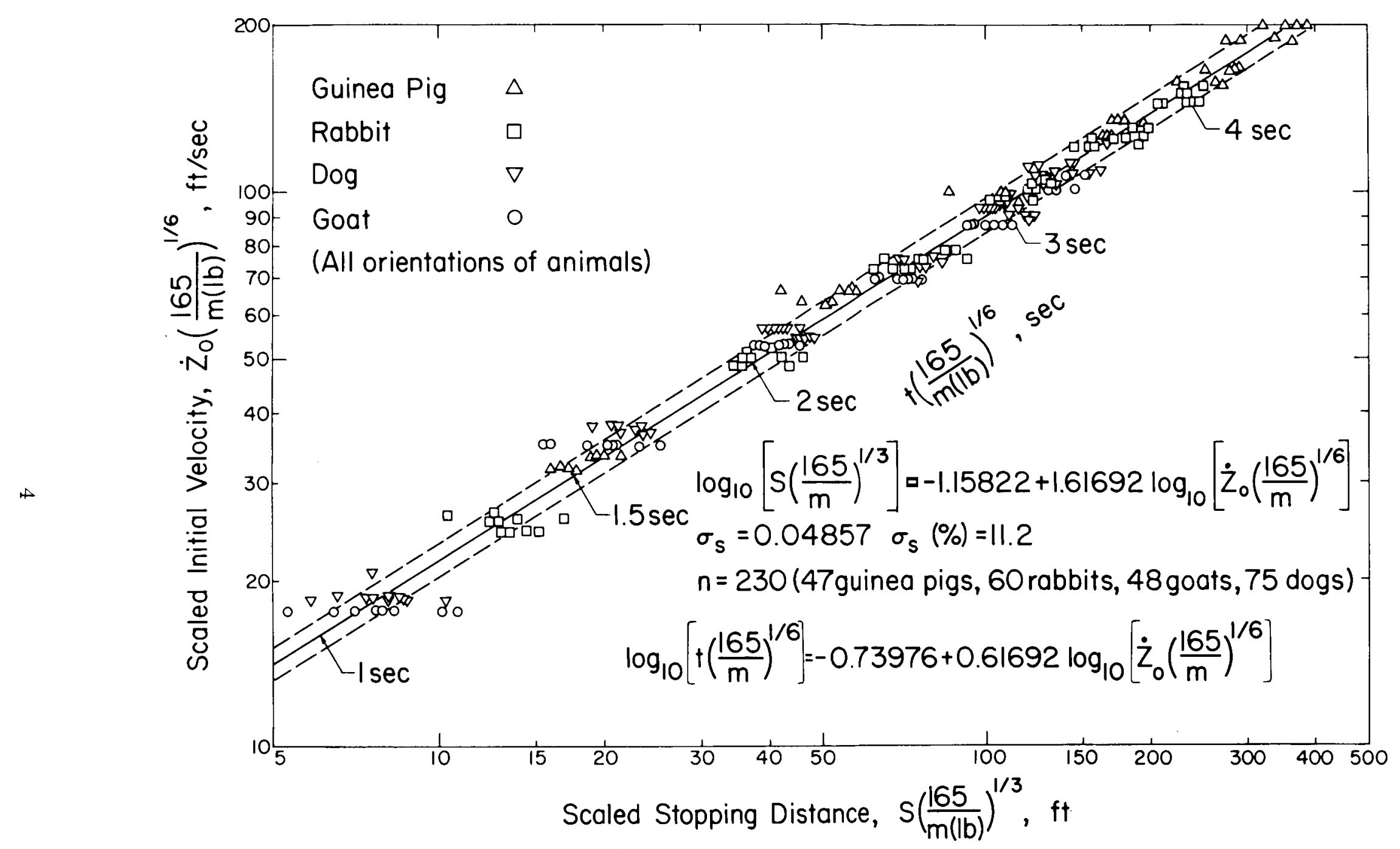

Figure 1. Initial velocity $\left(\dot{Z}_{0}\right)$ vs. displacement $(S)$ for animals as a function of mass $(\mathrm{m})$. Computed stopping times $(\mathrm{t})$ are also indicated. Dashed lines are drawn one standard error of estimate from the regression line. 
Since the equation in FIGURE 1 gives the scaled average stopping distance as a function of the scaled initial velocity, it is possible by differentiating to obtain the incremental increase in stopping distance associated with an incremental increase in initial velocity and thereby to obtain the average deceleration due to ground friction, $D_{a}=\dot{Z}_{o} d\left(\dot{Z}_{0}\right) / d S$, as a function of velocity and mass. The deceleration found in this manner was

$$
\mathrm{D}_{\mathrm{z}}=8.9029\left[\dot{\mathrm{z}}_{\mathrm{o}}(165 / \mathrm{m})^{1 / 6}\right]^{0.38308}
$$

where $\dot{Z}_{o}$ is in $\mathrm{ft} / \mathrm{sec}, \mathrm{m}$ in $\mathrm{lb}$, and $\mathrm{D}_{\mathrm{a}}$ in $\mathrm{ft} / \mathrm{sec}^{2}$. From this deceleration it is possible to compute the time required for the animal to come to rest. A few of these stopping times are indicated in FIGURE 1 on the scale labeled $\mathrm{t}(165 /)^{1} / 6$. Thus, the stopping times can be read directly for a 165-1b animal but must be computed for an animal of any other mass. In order to facilitate this cimputation, the equation for $t$ as a function of $\dot{Z}_{0}$ and $m$ is also given in FIGURE 1 .

Unlike the animal displacements, those for the stones showed no variation with mass over the range of the stone sizes tested ( 1.3 to $116 \mathrm{lb}$ ); i.e., stone displacements are a function of initial velocity but not of mass. The concrete-block displacements, on the other hand, did vary with orientation, again unlike those for animals, but when the block data for all orientations vere combined, there was no significant difference between either the hollow - or the filled-block displacements and the stone displacements. Consequently, in order to predict the displacements of either stones or blocks dropped in random orientations, all the stone and block data were analyzed together as shown in FIGURE 2. The datum points represent the geometric means of the particular group of blocks or stones. The number of individual experiments in each group is indicated near the plotted points. (Individual rather than grouped data were used in the regression analysis.) The spread in the data. is so large that the total cisplacements for only about 68 percent of similar individual experiments can be predicted with 41 percent. The stone and block displacements have a greater variability than the animal displacements because the motion of the stones and blocks is not as uniform as that of the animals. That is, animals always assume the same rolling orientation and tend to stay close to the ground whereas the stones and blocks are mostly airborne, the energy dissipated upon impact being greatly dependent on orientation as well as velocity. It should be noted that these objects were dropped from a truck at a height of approximately $2.6 \mathrm{ft}$ resulting in a vertical impact velocity of about $13 \mathrm{ft} / \mathrm{sec}$ in addition to their horizontal velocity, $\dot{Z}_{0}$. The deceleration for stones and blocks, $D_{s}$, was computed (as in the case of the animals) and found to be

$$
D_{s}=15.40\left[\dot{z}_{0}\right]^{0.0996}
$$

where, as before, $\dot{Z}_{0}$ is in $\mathrm{ft} / \mathrm{sec}$ and $D_{s}$ in $\mathrm{ft} / \mathrm{sec}^{2}$. A few stopping times, $t$, and the formula for computing them are also indicated in FIGURE 2 and were determined in the same manner as that used for computing the stopping times for animals. 


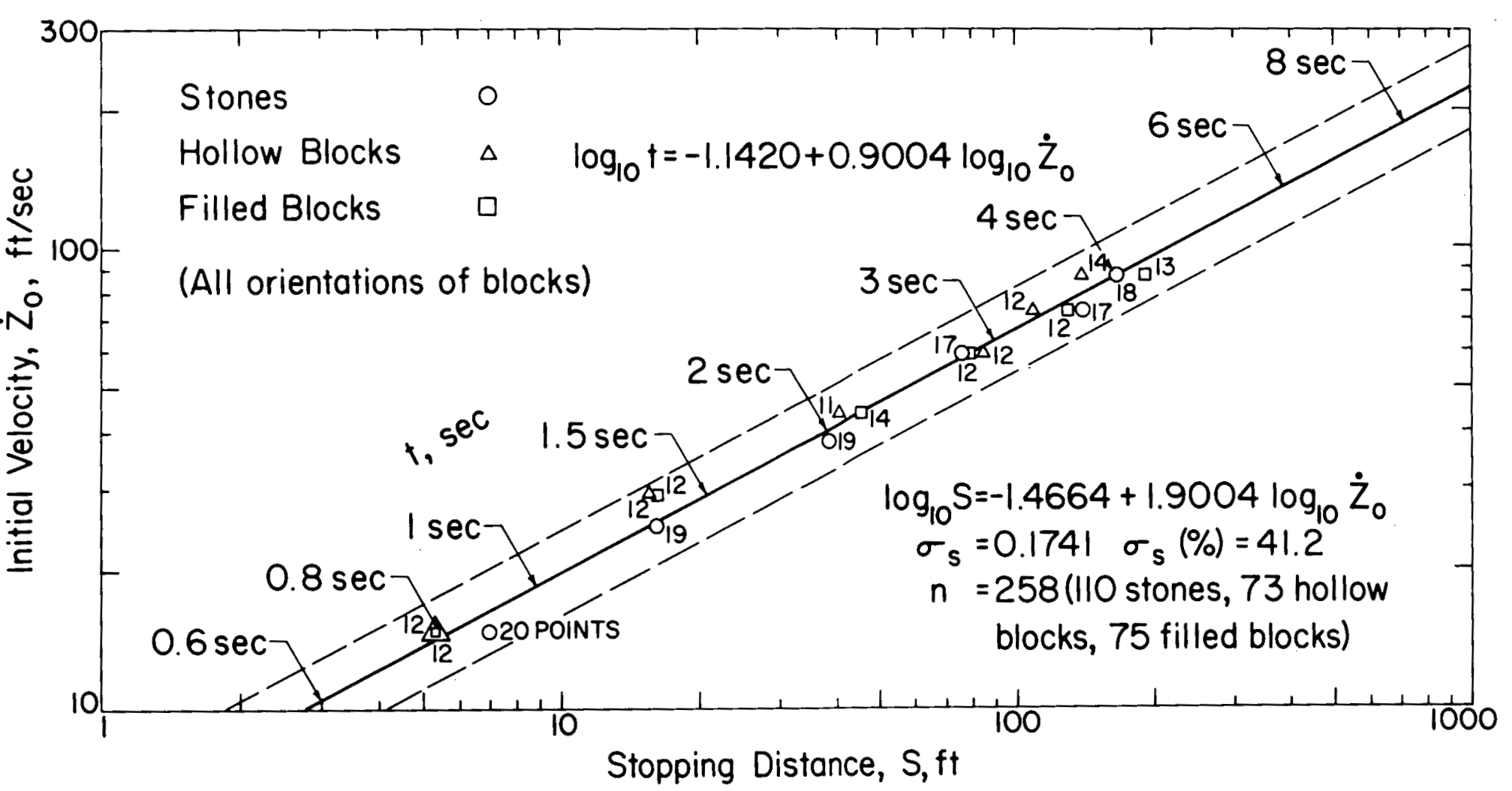

Figure.2. Initial velocity $\left(\dot{Z}_{0}\right)$ vs displacement $(S)$ for stones, hollow concrete blocks, and filled concrete blocks. Computed stopping times $(t)$ are also indicated. Dashed lines are drawn one standard error of estimate from the regression line. 
The animal displacements obtained in the "calibration" experiments have been compared (Fletcher, 1965b) to the results obtained by Anderson et al. (1961) where goats and dummies were blown from an open-end shock tube and tumbled to a stop over a "grassy pasture." Reasonably good agreement was found between the results of the two experiments considering the variations in the experimental techniques and the inherent differences between animals and dummies. The experimental stone and block displacements have not been compared to the results obtained by any other experimenters.

\section{SPHERE TRANSLA TION}

During Operation Snow Ball an experiment was conducted to measure for steel spheres of different sizes their blast-induced velocities ai approximately maximum value (Fletcher et al., 1965a). These velocities could then be related by means of the acceleration coefficient to those measured photographically for goats and anthropomorphic dummies in another experiment to be described later. The sphere velocities were also used to estimate the dynamic-pressure impulse at each of the three ranges where they were placed.

Impact velocities were determined by trapping the spheres in two-inch layers of expanded polystyrene (Styrofoam) and later measuring their depths of penetration. Two pieces (each $1 \mathrm{ft} \times 3 \mathrm{ft} \times 2$ in) of Styrofoam were used at each station placed at 965-, 790-, and 580-ft ranges where the predicted peak overpressures were 10,15 , and $30 \mathrm{psi}$, respectively. These installations were identified as $10 S B, 15 S B$, and $30 S B$, the number referring to the predicted overpressure and SB representing SnowBall. Each sheet of Styrofoam was cemented in a vertical position to a piling set in concrete with the bottom of the sheet at ground level (FIGURE 3). The spheres were located $4.0 \mathrm{ft}$ upstream from the Styrofoam at heights of $0.8,1.8$, and $2.8 \mathrm{ft}$ above the ground. The initial distance between the spheres and the Styrofoam was chosen from theoretical considerations to trap the spheres at approximately their maximum velocity. The spheres were placed with the centers two diameters apart in shallow holes (0.1 diameter deep) drilled in steel bars which were one inch wide and one-fourth inch thick. These bars were welded to vertical steel bars (FIGURE 3) set in the ground.

The geometric means and the geometric standard deviations of the impact velocities, V, (as computed from the depths of penetration) are shown in FIGURE 4 as a function of the acceleration coefficient, $a$, of the spheres. The curves are the predicted V-vs-a relations, obtained using the blast waves from the indicated references and the mathematical model of blast-induced translational effects. When this model was used to compute the sphere-impact velocities, it was assumed that the spheres were in free air (since they do not impact the ground in translating from their mount to the Styrofoam) and that their acceleration coefficients were those based on a drag coefficient of 0.47 (Hoerner, 1958). The calculations were discontinued after the spheres had traveled four $\mathrm{ft}$, the point at which they should impact the Styrofoam. 
$\infty$

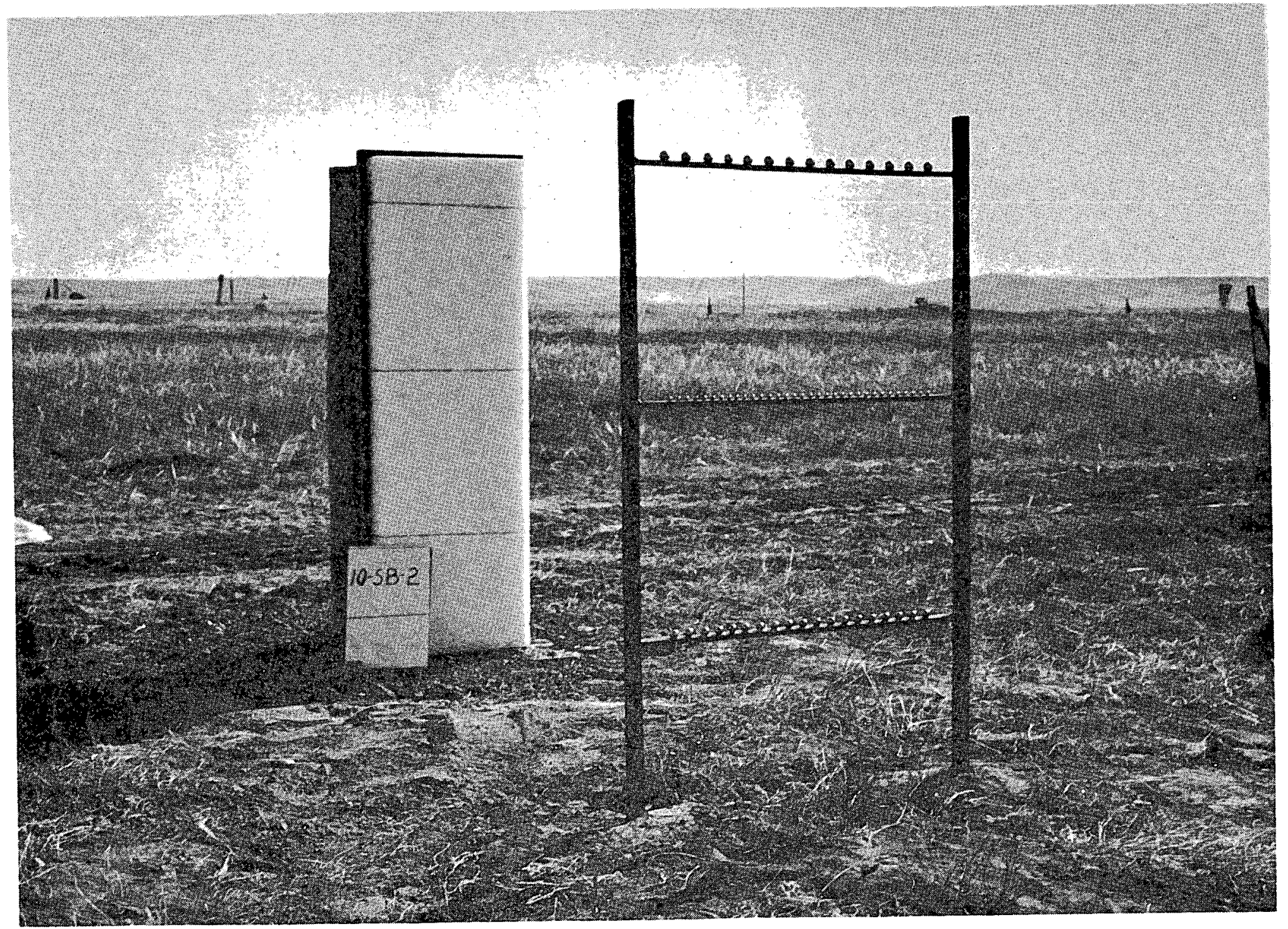

Figure 3. Preshot picture looking away from ground zero of one of the two steel-sphere installations at $10 \mathrm{SB}$. 


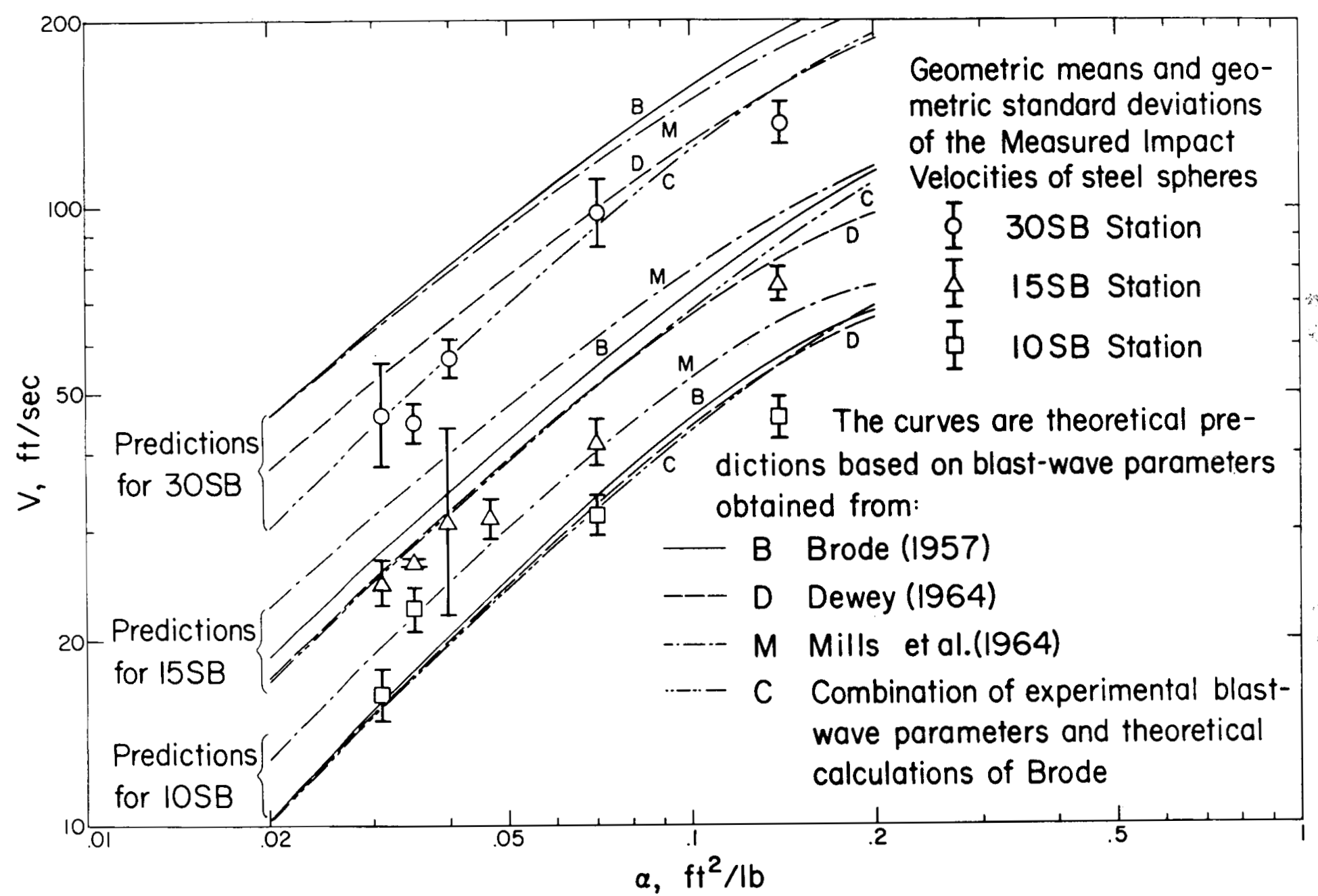

Figure 4. Measured impact velocity $(V)$ as a function of acceleration coefficient $(a)$ for each of the three stations. The curves are the predicted $V$ vs a relations obtained using blast waves from the indicated references. 
The curves based on Brode's work (1957) were obtained by finding the reflection factor for a surface burst which would predict the measured peak-overpressure-vs-range relation from SnowBall. By using this reflection factor (2.55) along with the ambient pressure (13.67 psi) and ambient speed of sound $(1142 \mathrm{ft} / \mathrm{sec})$, the complete set of blastwave parameters could be obtained as functions of time. The curves computed with these parameters are somewhat high for $15 \mathrm{SB}$ and $30 \mathrm{SB}$, but seem to.correspond well to the data at 10SB. Part of the discrepancy may be explained by the fact that an unrealistically high reflection factor of 2.55 was necessary to obtain the correct overpressure vs range relation whereas a reflection factor of 1.63 was calculated for SnowBall by Keefer (1965). This high reflection factor (i.e., high yield) led to longer durations and correspondingly greater dynamic-pressure impulses and thus predicted velocities which are too great.

The curves based on Dewey's work (1964) fit the data much better, particularly at the 30SB station, although the predictions at $15 \mathrm{SB}$ and 30SB still appear to be somewhat high. The better fits are not surprising in view of the fact that Dewey's formulas are not strictly theoretical but rather are empirical fits to data gathered on smaller but similar shots (i.e., hemispheres of TNT placed on the ground). The deviations from the experimental velocities may result from the fact that Dewey's formulas are not realistic for times beyond the limit of the experimental data since they predict the winds will remain positive forever; i.e., the wind speed reaches a minimum value and then starts increasing without having gone negative. Although some of our experiments (see following section) actually did show evidence of an "extended" duration at the 10SB station, no such evidence was seen at the $30 \mathrm{SB}$ station of Operation SnowBall.

The velocity vs a curves based on the work of Mills et al. (1964) are high at all three stations. However, their data do predict the experimental peak overpressure-vs-range relation for a reflection factor of 1.63 , and their predicted durations for the positive overpressure are within 10 percent of those measured by Keefer (1965). It would thus appear that the dynamic-pressure impulses of Mills et al. are too large. Since the peak dynamic pressure can be determined from the peak overpressure and the Rankine-Hugoniot relations, apparently the dynamic-pressure impulses are too great because of an unrealistic shape factor or duration, or both. Note that the predictions based on the data of Mills et al. and Brode are in agreement for the 30SB station but that the predictions of Mills et al. become progressively higher than those of Brode as the overpressure decreases.

The curves labeled " $\mathrm{C}$ " in FIGURE 4 were computed using a combination of experimental blast-wave parameters and the theoretical calculations of Brode; i.e., the experimental peak overpressure and the experimental duration of the positive overpressure waves were taken from Minor (1964) and Keefer (1965), the peak dynamic pressure was computed from theory, the dynamic-pressure duration was calculated from a curve of (dynamic-pressure duration) / (positive-overpressure 
duration) vs (peak overpressure) taken from Brode (1957), and the overpressure and dynamic-pressure impulses were determined from curves of impulse vs overpressure also taken from Brode and based on a reflection factor of 1.63. The measured overpressure curves appeared to be nearly classical in shape, and from Dewey's measurements (1964) on previous shots, it was anticipated that at least the leading edges of the dynamic-pressure curves would also be near classical. For lack of more detailed information the overpressure curves were approximated by Friedlander equations with linear terms and the dynamic-pressure curves were approximated by Friedlander equations with square terms as is done in The Effects of Nuclear Weapons (Glasstone, ed., 1962), but a multiplicative factor was introduced into the exponent in all cases so that the desired impulses could be obtained. The negative phases of all these curves were not used, but this had a negligible effect on the computed impact velocities since (1) most of the spheres impacted before the negative phase arrived and (2) those spheres which did "see" the negative phase still spent most of the time traversing the four-ft distance in the positive phase and the pressures during the positive phase were much larger than the pressures during the negative phase. For all but the "C" curves, however, the negative phases were included directly as they were computed from the various sources (note that Dewey's dynamic-pressure curves did not have a negative phase but that his overpressure curves did).

The " $\mathrm{C}$ " curves seem to fit the data reasonably well indicating that Brode's impulses based on a realistic reflection factor are reasonable even though the corresponding predicted overpressure vs range relation is not. The computed velocities are much more dependent on dynamicpressure impulse than on duration; hence, the good agreement between the predicted and experimental sphere velocities does not necessarily mean that the predicted dynamic-pressure durations are close to the experimental values.

In a previous paper, (Fletcher et al., 1965a) dynamic-pressure impulses were estimated by the following procedure: The impact velocity vs a data at each station were approximated using a least-squares regression analysis of the form

$$
\mathrm{V}=\mathrm{K}_{1} a+\mathrm{K}_{2} a^{2}
$$

where $\mathrm{K}_{1}$ and $\mathrm{K}_{2}$ are constants. It was shown that the dynamic-pressure impulse can be taken to be equal to the regression coefficient $K_{l}$. The impulses estimated in this way appear in Table I under the column labeled "estimated from spheres." The impulses derived from Brode using a reflection factor of 1.63 and used in computing the "C" curves in FIGURE 4 are also listed in Table I under the column labeled "predicted by Brode." Note that these two estimates of the impulses are in fair agreement, the biggest difference being at the IOSB station. The dynamic-pressure impulses of Brode were adjusted (leaving all other 
TABLE I

DYNAMIC-PRESSURE IMPULSES IN PSI-MSEC

\begin{tabular}{lccc}
\hline Station & $\begin{array}{c}\text { Estimated. } \\
\text { from Spheres }\end{array}$ & $\begin{array}{c}\text { Predicted } \\
\text { brode (1957) }\end{array}$ & $\begin{array}{c}\text { Adjusted } \\
\text { Impuls }\end{array}$ \\
\hline $10 \mathrm{SB}$ & 140 & 120 & 130 \\
$15 \mathrm{SB}$ & 170 & 190 & 170 \\
$30 \mathrm{SB}$ & 340 & 340 & 340 \\
\hline
\end{tabular}

* Using a reflection factor of 1.63. These impulses were used in deriving the " $\mathrm{C}$ " curves in FIGURE 4.

** Adjusting the impulses to obtain curves which fit the data in FIGURE 4 better than the " $C$ " curves.

quantities including peak values and durations the same as used in computing the "C" curves) to find the impulses which best fit the data plotted in FIGURE 4. These "adjusted" impulses are also listed in Table 1 under the last column. Note that for $15 \mathrm{SB}$ and $30 \mathrm{SB}$ the values agree with the estimates from the regression analysis, but for $10 \mathrm{SB}$ the adjusted value is somewhat lower than the impulse estimated from the sphere data. This discrepancy apparently results from the fact that at the IOSB station the mean velocity of the spheres with an $a$ of $0.139 \mathrm{ft}^{2} / \mathrm{lb}$ is lower than what would be predicted based on the velocities of the other spheres captured at this station. This lower velocity would tend to increase the impulse estimated by the regression analysis and decrease the impulse estimated by the adjusted Brode analysis.

The close agreement of these impulses and the moderate scatter in the data indicate that the dynamic-pressure impulses can be approximated within the accuracy of the data by using the simplified regression analysis rather than using the translation model. This is a faster and simpler approach which still allows dynamic-pressure impulses from shortduration blast waves to be computed to a reasonable degree of accuracy without the details of the blast-wave parameters being considered as functions of time.

\section{ANIMAL AND DUMMY TRANSLATION}

During Operation Snow Ball an experiment (Bowen et al. , 1965) was also conducted to determine, with motion pictures, displacement and velocity as functions of time for goats and anthropomorphic dummies placed at the same ranges as the 10SB, 15SB, and 30SB sphere stations. 
Other objectives were to measure the total displacements of the experimental objects, to study the tumbling mechanisms during displacement, and to compare the measured velocities with those predicted with the spheres.

At each station two dummies and one goat were placed on an asphalt pad on which a grid had been painted and which was lined on either side with stripped poles, both serving as reference lines in the field of view of two cameras mounted on $18-\mathrm{ft}$ towers placed on either side of the pad. The anthropomorphic dummies used in this experiment weighed $165 \mathrm{lb}$ and their joints were adjusted to give sufficient tension for the dummy to stand erect. One dummy was standing, facing away from the blast, and the other dummy was prone, face down, with its head toward the blast. The vertical dummy was supported by leaning it approximately $2^{\circ}$ from the vertical against a horizontal section of pipe at about the level of the small of the back. The goats, which had been sacrificed with an overdose of anesthesia about three hours before the shot, were supported in a normal standing position side-on to the winds with the aid of a rack designed in such a way that translation was unhindered. Thus, both the goats and the standing dummies presented a maximum area to the oncoming blast wave.

To aid in the interpretation of the film records, the positions at various times of the initially-standing dummy and the goat were sketched on a single drawing of the asphalt pad as shown in FIGURE 5 for the $10 S B$ station. The dummy moved out feet first without any apparent rotation about its long axis. For a time the resulting airfoil tended to keep the dummy airborne, the first impact being on the dummy's head after about $547 \mathrm{msec}$ and 15-ft displacement as indicated by outline (h) in FIGURE 5 . Note that the goat's head and feet initially moved ahead of the trunk resulting in an orientation which would cause the blast winds to deflect the motion of the goat to the right and upward. The effect due to the head motion took precedence over that due to the foot motion causing the goat to impact on its feet with the head in a forward position after a displacement of about $11 \mathrm{ft}$ as shown by outline (f) in FIGURE 5. Note that both the dummy and the goat deflected to the left. This is a result of non-radial winds which were clearly visible on the films. The motion of the initially prone dummy is not shown because it was rapidly obscured by dust.

The dummies and goat at the $15 \mathrm{SB}$ station were obscured by dust after about $200 \mathrm{msec}$ but until that time they behaved in a manner similar to those at $10 \mathrm{SB}$. One difference, however, was that at $15 \mathrm{SB}$ the standing dummy's arms were blown forward thus reducing the total drag area. At the $30 \mathrm{SB}$ station all experimental objects were obscured by dust immediately upon arrival of the blast wave so that no analysis of the film records was possible.

The complete time-displacement histories of the goats and dummies were computed with the translation model (including the ground friction), 


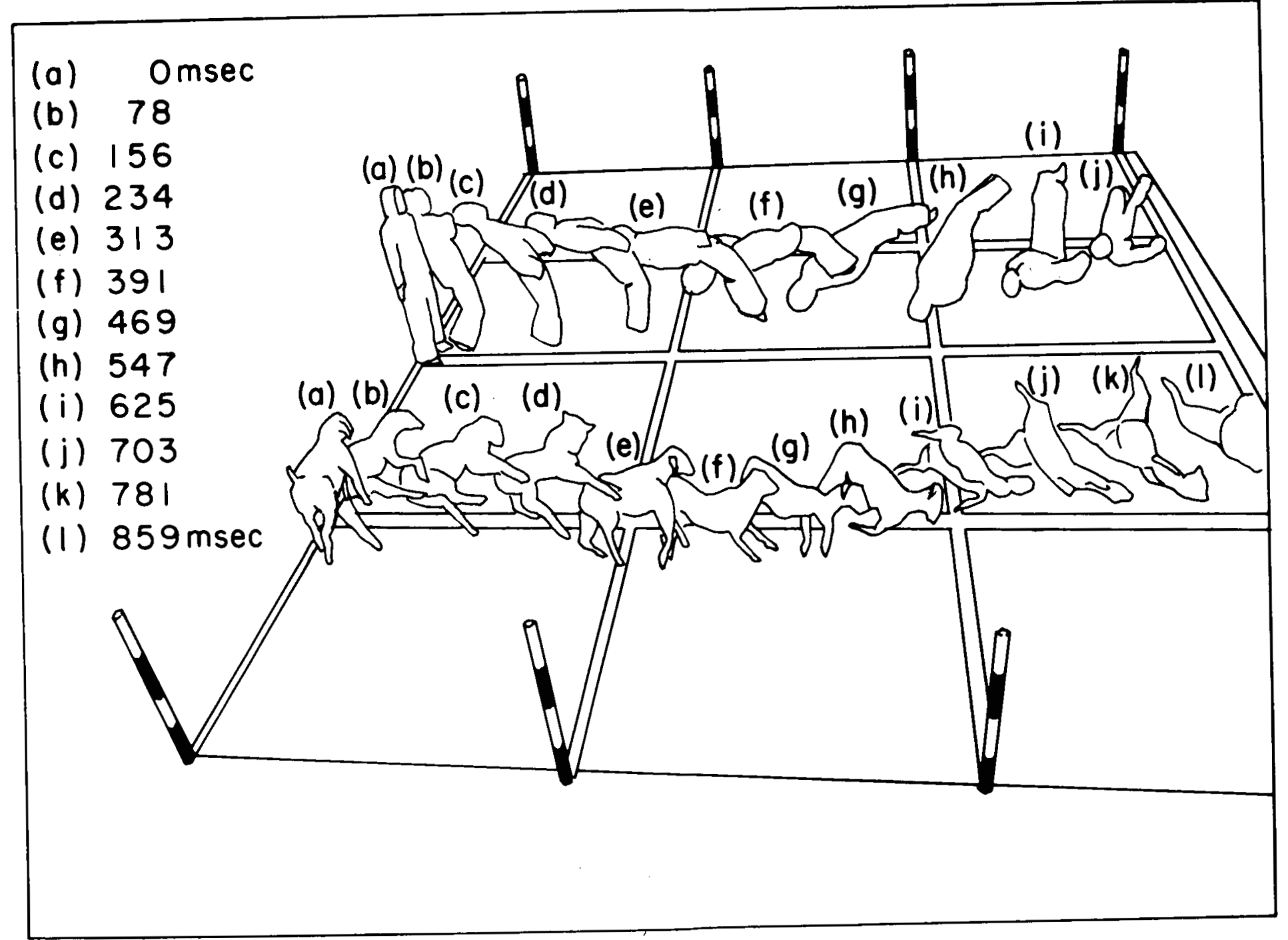

Figure 5. Dummy station 10SB composite drawing showing the positions of the initially-standing dummy and goat at the indicated times after the arrival of blast waves. 
using the same blast waves that were assumed in computing the " $\mathrm{C}$ " curves in FIGURE 4, since these waves had predicted the sphere velocities fairly accurately. Because most of the acceleration phase is over before much rotation has occurred, the acceleration coefficients of the standing dummy and goat were assumed to remain constant at their initial values of 0.052 and $0.046 \mathrm{ft}^{2} / \mathrm{lb}$, respectively, during the entire translation in order to simplify the calculations. This approximation would not be justified in cases where the duration of the blast wave is long enough to allow dummies and goats to rotate appreciably before the winds have passed (Taborelli et al., 1959). Results of the calculations for the standing dummies and goats are plotted in FIGURE 6 in the form of velocity-vsdisplacement curves, the points and straight lines representing the experimental data. The straight-line segments represent measured velocities which appeared to be constant over a range of several feet beyond a displacement of about two feet. The datum points indicated by circles are the measured total displacements and the points indicated by squares are the velocities after a displacement of four ft as computed from the polynominal fits to the sphere data (Fletcher et al., 1965a) making use of the initial $a^{\prime} s$ of the dummies and goats.

At the $30 \mathrm{SB}$ station the predictions about both the dummy and the goat agree reasonably well with the measured total displacements and the velocities estimated from the sphere data (no analysis of the film records was possible at this station because of the dust). At the $15 \mathrm{SB}$ station the computed and measured velocities of the dummy and goat are in close agreement as are the computed and measured total displacements of the dummy, but the measured displacement of the goat $(48 \mathrm{ft})$ is considerably greater than the predicted displacement $(2.3 \mathrm{ft})$. At the $10 \mathrm{SB}$ station all of the computed velocities and displacements are significantly lower than the experimental values. It is thus evident that in three out of six cases there is good agreement between the experimental data and the computed time-displacement histories, and in the three other cases the agreement is poor. It was also noted that in the three cases where the agreement was good, the average angular deviation from the radial (measured from the initial to the final position) was $2.5^{\circ}$ with two objects deviating to the left and one to the right.

However, in the three cases where the agreement was poor, the average angular deviation from the radial was $14^{\circ}$, all three trajectories being to the left. This suggested that the anomalous velocity-vs-displacement histories were in some way connected with the anomalous non-radial winds which had been observed in the pictures taken at the $105 B$ station.

Several other observations provide further evidence for the presence of an anomalous wind pattern at $10 \mathrm{SB}$. The velocity of the initiallystanding dummy increased from 30.4 to $33.7 \mathrm{ft} / \mathrm{sec}$ about $0.5 \mathrm{sec}$ after the blast wave arrived even though the dummy was in tumbling contact with the ground by this time. This seems to indicate the presence of positive winds long after the main overpressure wave had passed. "The trajectory of the dummy was initially about $9^{\circ}$ to the left of a radial line but must have changed during the latter portion of translation

* The measured duration of the positive overpressure pulse was

$0.23 \mathrm{sec}$. 
Displacements and velocities determined from film records

口 Velocities after $4 \mathrm{ft}$ of travel estimated from sphere data

- Measured final displacements

The curves represent the theoretical displacement vs velocity data obtained with the translation model
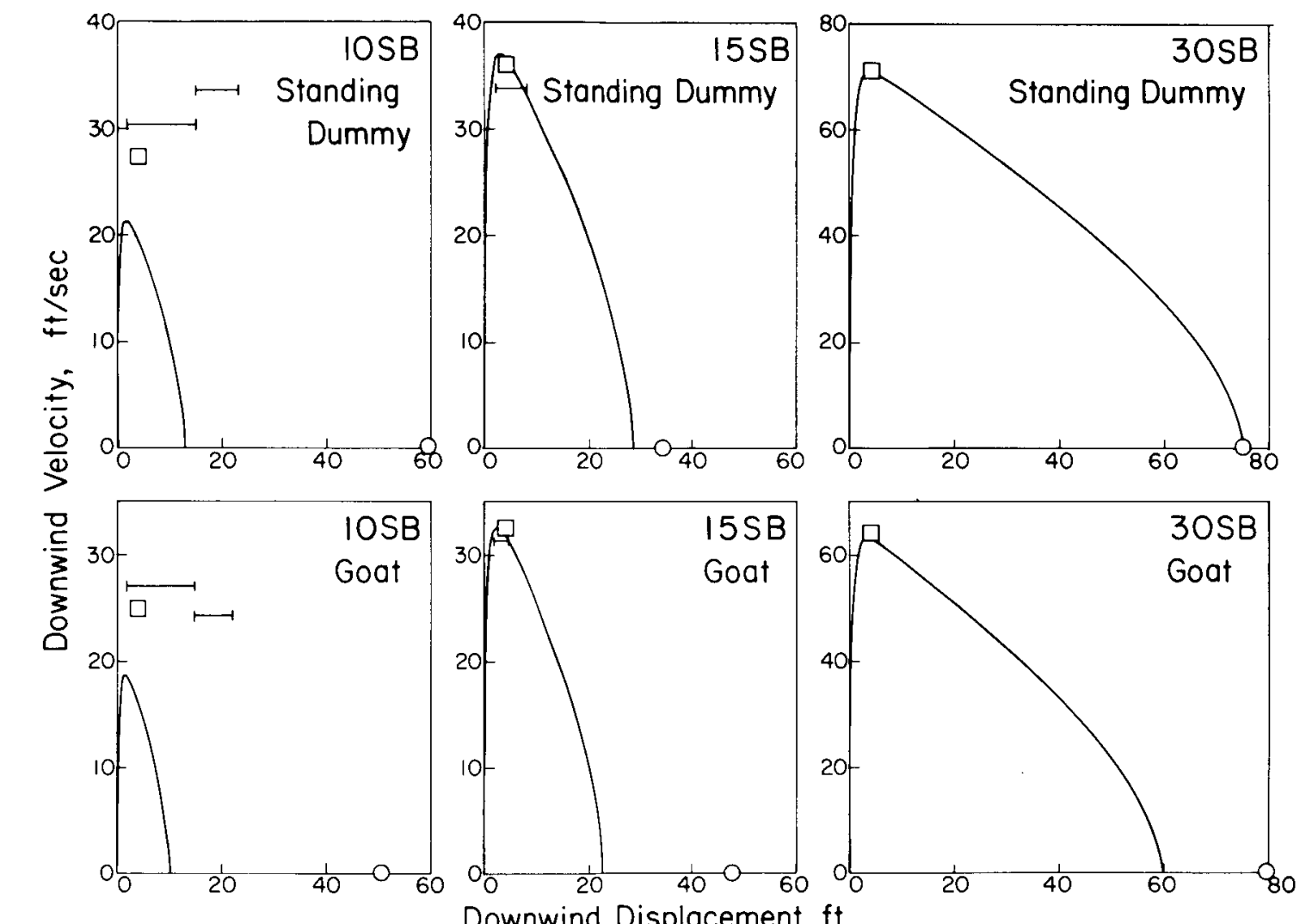

Figure 6. Velocity vs displacement for the standing dummies and goats. The straight-line segments represent the camera measurements, the circles the measured total displacements, the squares the estimates based on the sphere experiments, and the curves the theoretical predictions which were computed with the translation model. 
since it was found $19^{\circ}$ to the left. It might be argued, however, that the additional deflection could have been caused by the random nature of the decelerative tumbling. The total radial displacement of the dummy was about $60 \mathrm{ft}$ although the corresponding dummy at 15SB (175 ft nearer to ground zero) with about the same maximum velocity was displaced only 34 feet. The behavior of the prone dummy (which was placed on its face with the head toward ground zero) at $10 \mathrm{SB}$ indicated the presence of non-radial winds. Although the average radial displacement was only 1. $0 \mathrm{ft}$, the dummy had been rolled over to a back-down position, the head and feet having moved $3.5 \mathrm{ft}$ and $6.3 \mathrm{ft}$ to the left, respectively.

In an effort to understand the anomalous wind pattern, FIGURE 7 was prepared showing the 10SB, I5SB, and 30SB dummy stations and indicating the initial and final positions of the goats and dummies as well as the predicted final positions. Although the anomalous winds probably did not have a sharp boundary, apparently they were fairly localized in that the goat at the $15 \mathrm{SB}$ station suffered a much greater angular deviation than did the standing dummy $\left(10.6^{\circ}\right.$ as opposed to $\left.3.0^{\circ}\right)$ which was initially only $8 \mathrm{ft}$ from the goat. In view of this, a line was drawn on FIGURE 7 to indicate the approximate boundary of the anomalous winds. The line was drawn at an angle of $14^{\circ}$ with respect to the radial since this was the average angular deviation of the three objects presumed to be in the anomalous winds. Note that the U.S. blast line was situated well outside the apparent boundary of the non-radial winds and hence no blast-wave instrumentation was available in the region of the anomalous. winds. There is no indication that any of the sphere stations, which in all three cases were located more than $200 \mathrm{ft}$ circumferentially from the dummy stations (FIGURE 7), were affected by anomalous winds; however, non-radial winds would be difficult to detect since the distance of travel of the spheres was only four feet. Unfortunately, the above analysis does not indicate the causes of the anomalous winds nor the frequency of occurrence.

\section{STONE AND BLOCK TRANSLATION}

In 1957 during Operation Plumbbob, experiments were conducted on two nuclear shots to study stone and block translations (Bowen et al., 1963). One of these experiments will be described since the interpretations of the results are applicable to the problem of translational effects from conventional explosions. On Shot Galileo (11 kt, 500-ft HOB), a concrete-block wall was constructed at a ground range of $2750 \mathrm{ft}$ to study the breakage and displacement of the blocks due to the blast wave. This wall (FIGURE 8, preshot view) which weighed about four tons and contained 236 concrete blocks ( $7.5 \times 7.5 \times 16$ inches, 34 lb) was located on level, graded ground. FIGURE 9 is a view of the wall after it had been struck by a near-classical blast wave with a peak overpressure of 8.7 psi and a duration of 0.58 seconds. Note that many of the blocks remained intact and that some of them were apparently stopped by the 


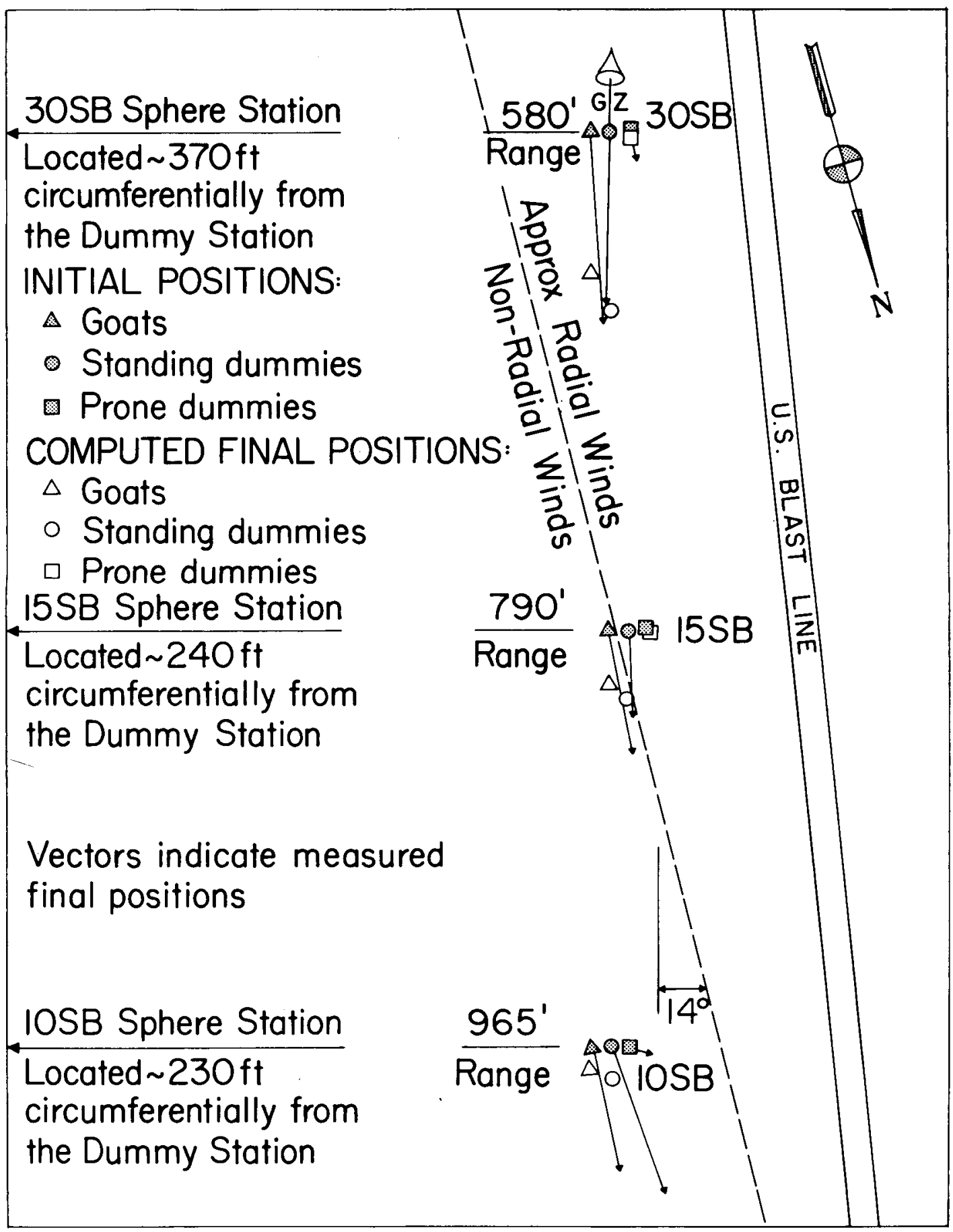

Figure 7. Layout of the three dummy stations showing the initial and final positions of the goats and dummies as well as the predicted final positions. The approximate boundary of the anomalous winds is also indicated. 




Figure 8. Preshot view of concrete-block wall ( $64 \mathrm{in.} \mathrm{high,} 40 \mathrm{ft}$ long, and $7.5 \mathrm{in}$. thick), Galileo shot. 


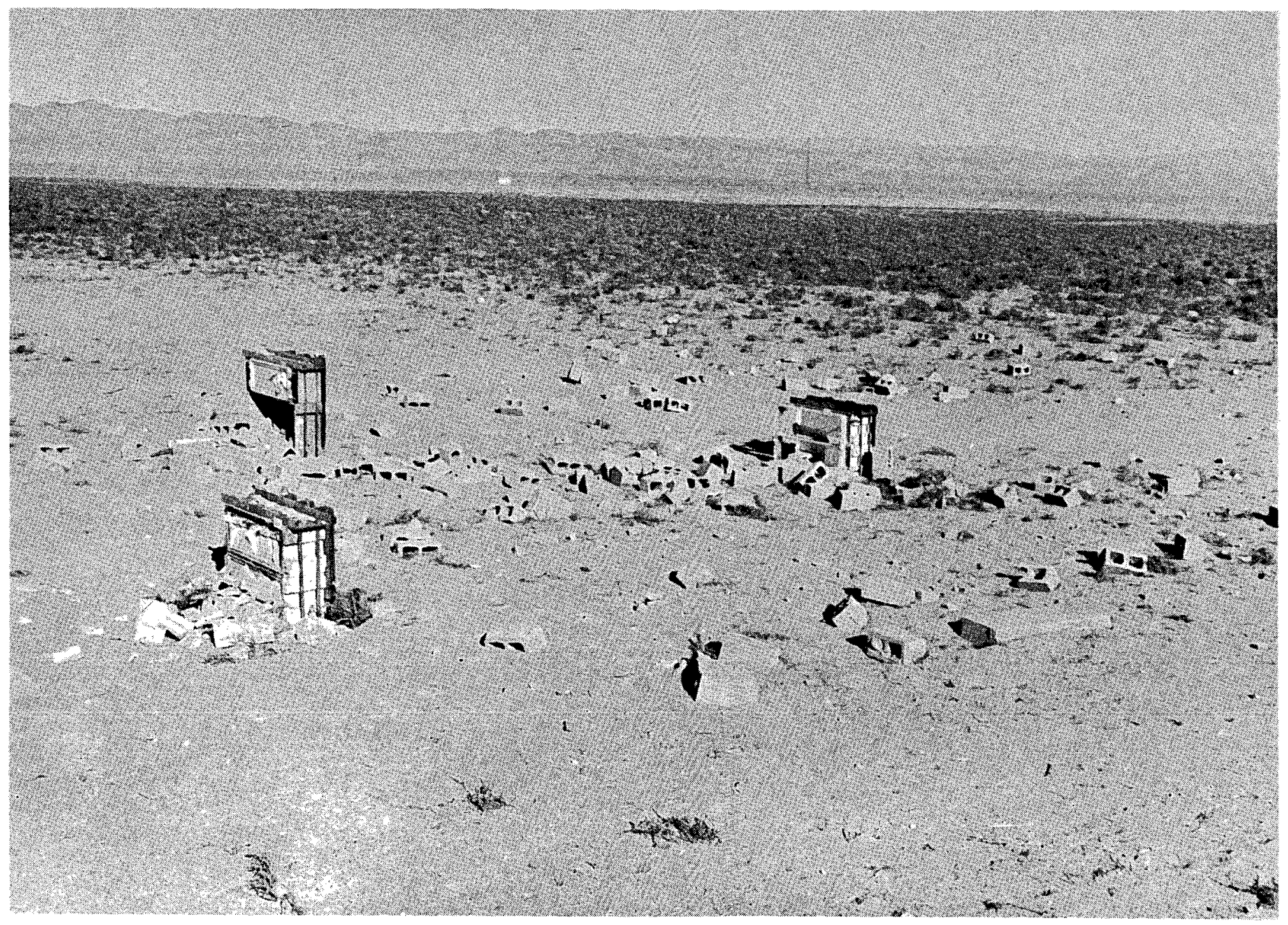

Figure 9. Postshot view of the fragments of the concrete-block wall. 
three Styrofoam missile traps placed behind the wall (FIGURES 8 and 9). Final resting positions for the larger wall fragments (whole, half, and joined blocks) are plotted in FIGURE 10. One block (not plotted but indicated at the top of the chart) was found as far as $403 \mathrm{ft}$ downstream and $170 \mathrm{ft}$ to the left of the center of the wall. Note the absence of blocks behind the trap installations.

In order to estimate the velocities of the wall fragments from their total displacements, it was necessary to use the relation for initial velocity vs displacement for stones and blocks as determined from the calibration experiments described in a previous section. Further, it was necessary to make three simplifying assumptions: (1) The wall fragments achieved their peak velocity before they were displaced any significant distance. This is approximately true for objects with low acceleration coefficients such as those for the larger wall fragments, $\leqslant 0.03 \mathrm{ft}^{2} / \mathrm{lb}$. In effect, this assumption allows us to neglect the blast wave and to simply think of the wall fragments as having started off with an "initial velocity." (2) These "initial velocities" were horizontal (no vertical component) and followed a log normal distribution, sometimes called a geometric distribution. (3) All the blocks from each of the eight layers of blocks first impacted the ground at the point predicted by the geometric mean "initial velocity, "the height of the layer above ground, and the acceleration of gravity. This is an approximation since the actual first impact points would be scattered about this distance due to variations in the "initial velocities."

With the above assumptions it is possible to compute the distribution of displacements if a geometric mean initial velocity and a geometric standard deviation are assumed. The best values of these parameters were determined by trial and error and the results of this analysis are shown in FIGURE 11 where the downwind distance, $d_{x}$, is plotted against the percent of the wall fragments traveling less than the indicated distance. The circles on this plot represent the experimental cumulative distribution of the 155 wall fragments and the curve represents the theoretical distribution for a geometric mean velocity of $32 \mathrm{ft} / \mathrm{sec}$ and a geometric standard deviation of 1.55. Since these two parameters affect the curve in different ways (changing the velocity tends to translate the curve while changing the standard deviation tends to tilt the curve), both are closely determined by the process of fitting the data, a change of as little as 4 percent in either the geometric mean initial velocity or the geometric standard aeviation producing a curve which clearly does not fit the data as well as the curve shown in FIGURE 11 . However, because of the approximations and the large scatter in the data, this does not mean that the true values lie within 4 percent of the estimates, but it does show that the possible errors introduced by the process of fitting the data are relatively small.

In another experiment at the same range as the block wall, steel spheres were trapped in Styrofoam at approximately their maximum velocity. It was shown that the sphere velocities agreed well with those 


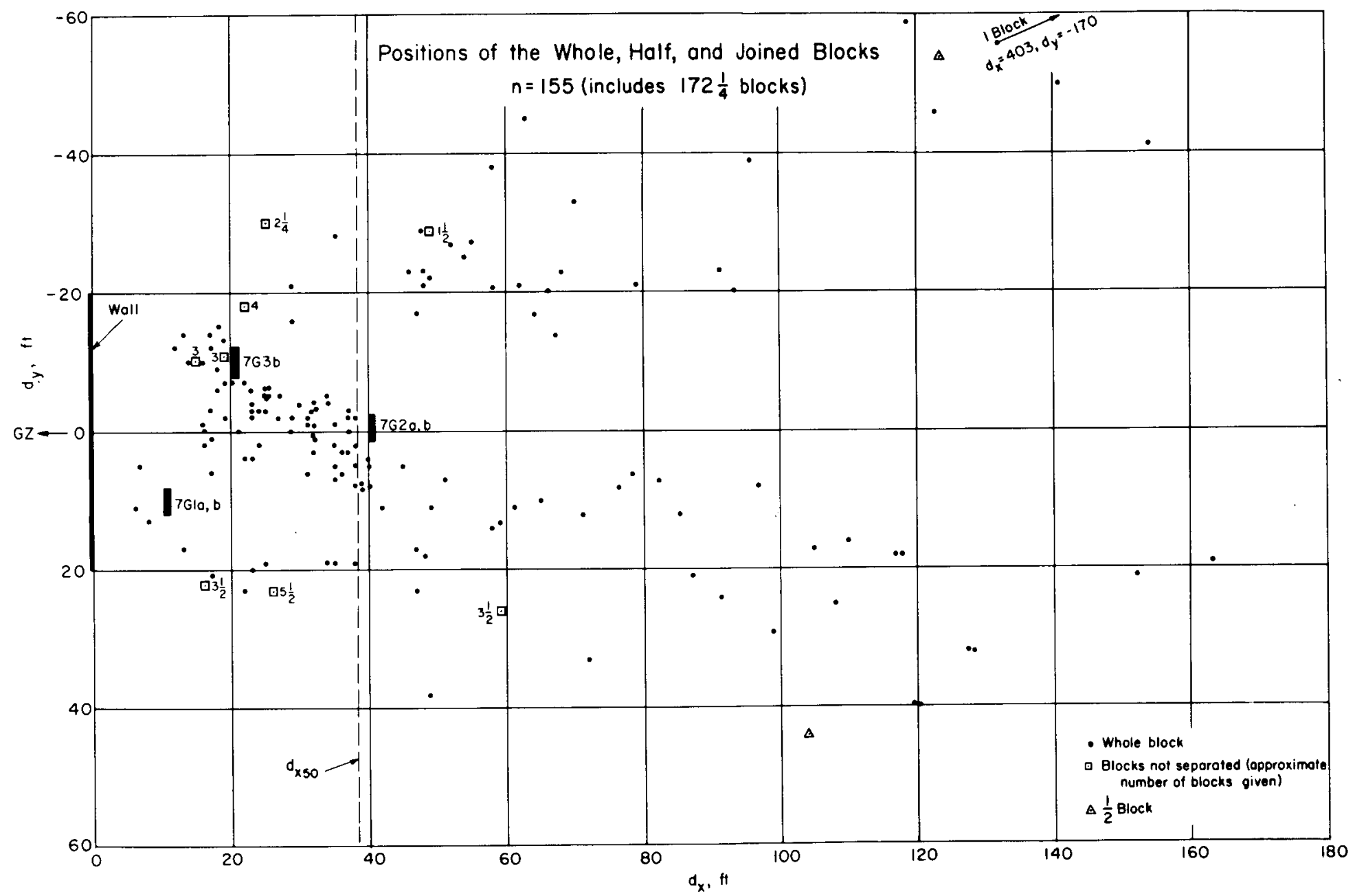

Figure 10. Spatial distribution of the larger wall fragments (whole, half, and joined blocks). 


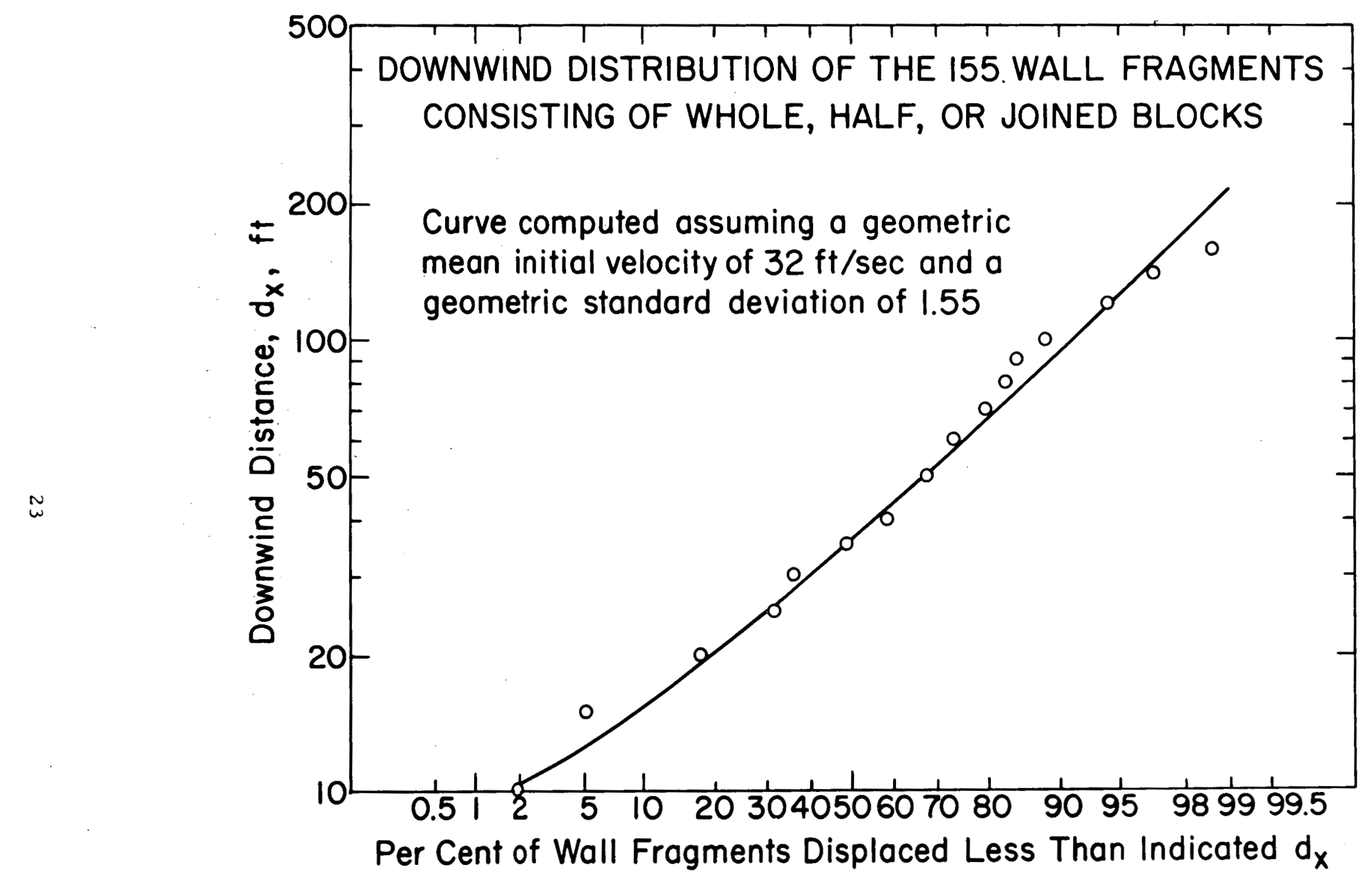

Figure 11. Downwind distribution of the whole, half, and joined blocks from the concreteblock wall. The points represent the actual distribution and the curve is the predicted distribution. 
computed with the earlier translation model (Bowen et al. , 1963).

Using an average initial acceleration coefficient $\left(0.0263 \mathrm{ft}^{2} / 1 \mathrm{~b}\right.$ assuming a drag coefficient of 1.07) for the blocks in the wall, a peak velocity of 30 to $33 \mathrm{ft} / \mathrm{sec}$ would be predicted from the sphere data. This is in excellent agreement with the geometric mean initial velocity of $32 \mathrm{ft} / \mathrm{sec}$ computed from the block displacements, indicating that velocities of blocks from walls can be reasonably estimated by assuming the free-field blast wave and using the initial acceleration coefficient of the blocks at least in the lower pressure regions and for similar types of block walls which are not reinforced. There is, however, the possibility that the true geometric mean velocity was a little higher than $32 \mathrm{ft} / \mathrm{sec}$ since some of the displacements would probably have been greater if the traps had not been located behind the wall. This effect is probably small because at least some of the blocks striking the traps were fragmented by the impact and hence were not included in the "larger" fragments used in this analysis.

\section{DECELERATIVE TUMBLING MODEL}

A mathematical model of decelerative tumbling was developed (Fletcher, 1965b) to study the mechanisms of tumbling of the stones, blocks, and animals and to be able to extrapolate to greater initial velocities than those used in the experiments. In this model, a twodimensional rigid object is assumed to slide, roll, lift-off, and impact along perfectly horizontal ground where the interactions between the ground and the object are through the coefficients of sliding and rolling friction and the coefficient of restitution (assumed to be zero). The shape chosen for the translated object was a "generalized ellipse" of the form $(x / a)^{n}+(y / b)^{n}=1$ where $1<n<\infty$. By choosing appropriate values of $a, b$, and $n$, the object can be made to approximate rectangular blocks or rocks and animals with various degrees of roundness.

It is of interest to note the mechanisms of the model by which objects lift off the ground, particularly since the coefficient of restitution between the ground and the object is assumed to be zero and therefore the objects do not bounce in the usual sense of the word. When the force (frictional and normal) of the ground against the object is in such a direction as to result in an upward component of velocity, the object can lift off. In general then, without the sliding frictional force, the object would slide and roll (rather than bounce) until it came to rest because of the rolling friction losses.

Because of the complexity of the mathematical model, computations were performed on an electronic digital computer. FIGURE 12 shows some of the computed output for an object with major and minor axes of 1.0 and $.05 \mathrm{ft}$, respectively, $(\mathrm{n}=3)$ which had an initial horizontal velocity of $100 \mathrm{ft} / \mathrm{sec}$, an initial downward velocity of $10 \mathrm{ft} / \mathrm{sec}$, and no initial angular velocity (the physical constants are indicated on the figure). The height of the center-of-mass, angular velocity, distance traveled, and energy per unit mass are all plotted as functions of time. 


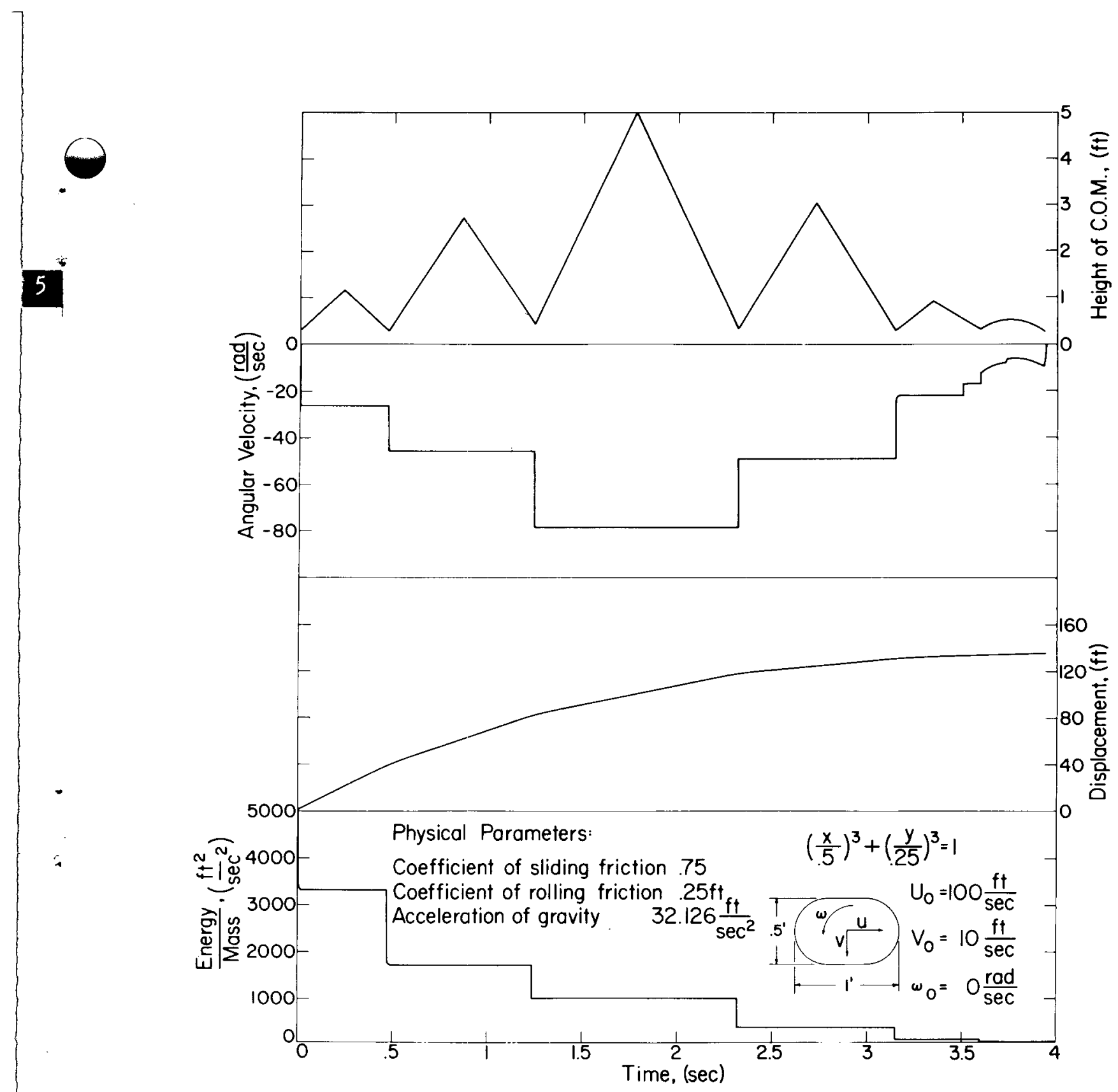

Figure 12. Some of the translation parameters computed using the decelerative tumbling model. The shape of the object being displaced as well as its initial velocity and orientation are indicated in the lower fourth of the figure. 
Note that the velocity and energy are "discontinuous" when an impulsive impact occurs. When the object is airborne, the height-above-ground curve should be parabolic rather than triangular as plotted by the computer for the sake of simplicity; however, the peak heights as shown in FIGURE 12 are correct. Note that the object is airborne most of the time, this being typical of the actual motion of stones and blocks but not of the rounder softer animals.

The first detailed calculations made with the mathematical model were designed to simulate the motion of the concrete blocks dropped from the moving truck and described in a previous section. Values of rolling and sliding friction coefficients were estimated and subsequently adjusted in order to achieve reasonable agreement with the experimental results. During the experiments eight blocks were dropped at $29.3 \mathrm{ft} / \mathrm{sec}$ with their long axis perpendicular to the motion, four dropped on edge, and four flat on one face. FIGURE 13 shows both the computed and the measured distances as a function of bounce number. To introduce scatter into the theoretical data, five calculations were made for each orientation; these runs assumed the block was dropped at exactly the desired angle and at $\pm 5^{\circ}$ and $\pm 10^{\circ}$ from the desired angle. Notice that, after the first bounce, both the theoretical and experimental dafa divide into two groups according to orientation. The curve in FIGURE 13 separates both the theoretical and experimental distances associated with one orientation from the same values associated with the other orientation (after the first bounce).

FIGURE 14 is a plot of initial horizontal velocity vs total distance traveled for all the blocks dropped in the two orientations shown in FIGURE 13. The 53 experimental drops are approximately divided evenly among six velocities: $14.7,29.3,44.0,58.7,73.3$, and $88.0 \mathrm{ft} / \mathrm{sec}$. Again the scatter in the theoretical runs was obtained by assuming the blocks were dropped at exactly the desired angle and at angles deviating from this angle by $\pm 5^{\circ}$ and $\pm 100^{\circ}$ Thus five runs were made for each orientation, or a total of ten theoretical runs for each velocity. Similar to those in FIGURE 13, the theoretical points in FIGURE 14 are slightly displaced on the ordinate so they can be easily distinguished from the experimental points. Note that neither the theoretical nor the experimental points are separated by orientation as they were in FIGURE 13.

From FIGURE 13 and FIGURE 14 it can be seen that the theoretical and experimental results for blocks agree closely in average displacement and scatter in the displacements. Stone displacements can be computed by averaging the total displacements associated with all orientations of the blocks as is indicated in FIGURE 2. At this writing, no attempt has been made to compute the decelerative tumbling process for animals.

\section{DISCUSSION}

In addition to the translational effects discussed in this paper, there are several other related areas of interest which are important, but have not been included because of space limitations. Some of these effects 


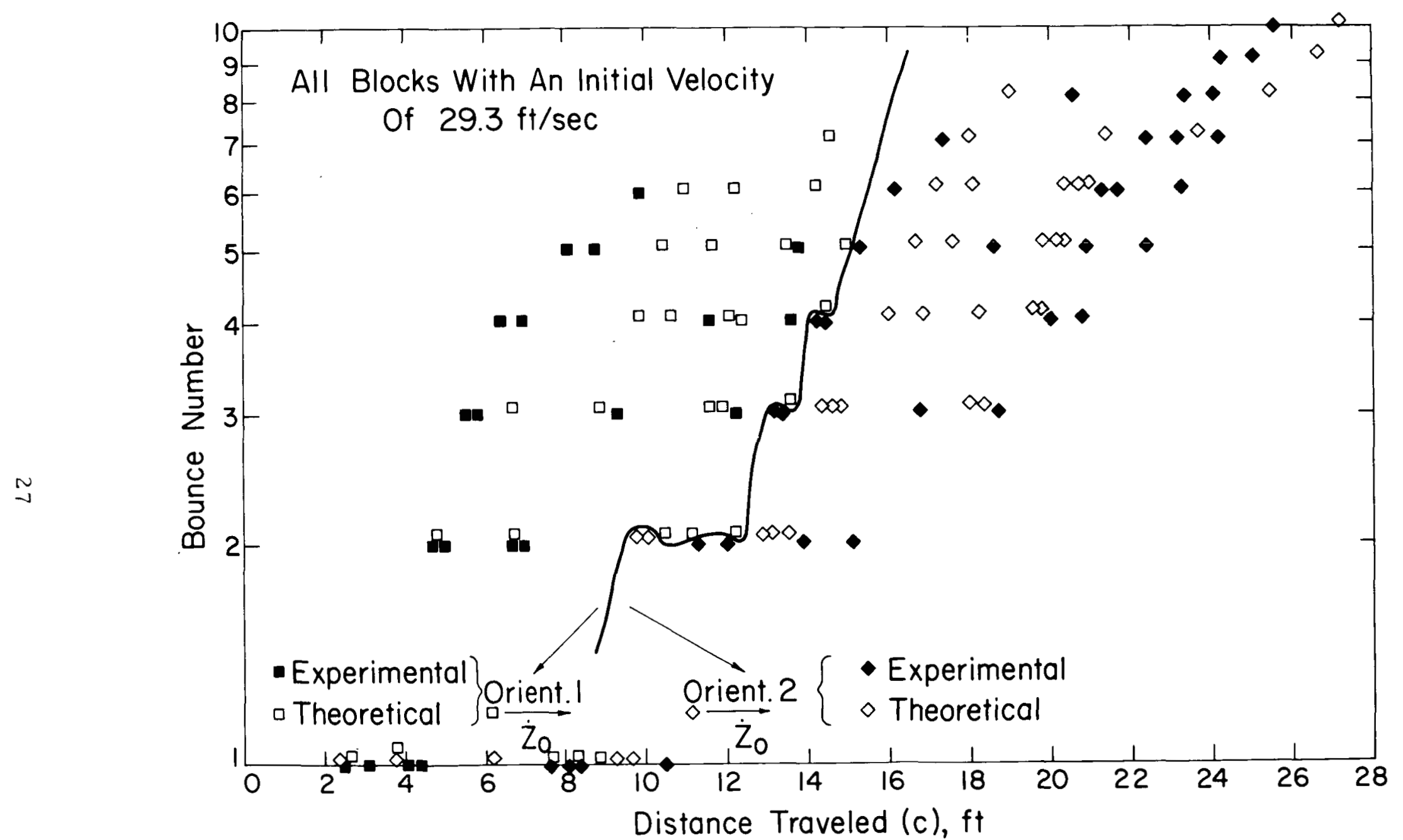

Figure 13. A comparison of experimental results with those computed with the decelerative tumbling model. Distance traveled is plotted as a function of bounce number for hollow and filled blocks with an initial velocity of $29.3 \mathrm{ft} / \mathrm{sec}$ and impact orientations indicated by the symbols representing cross-sections of the blocks. 


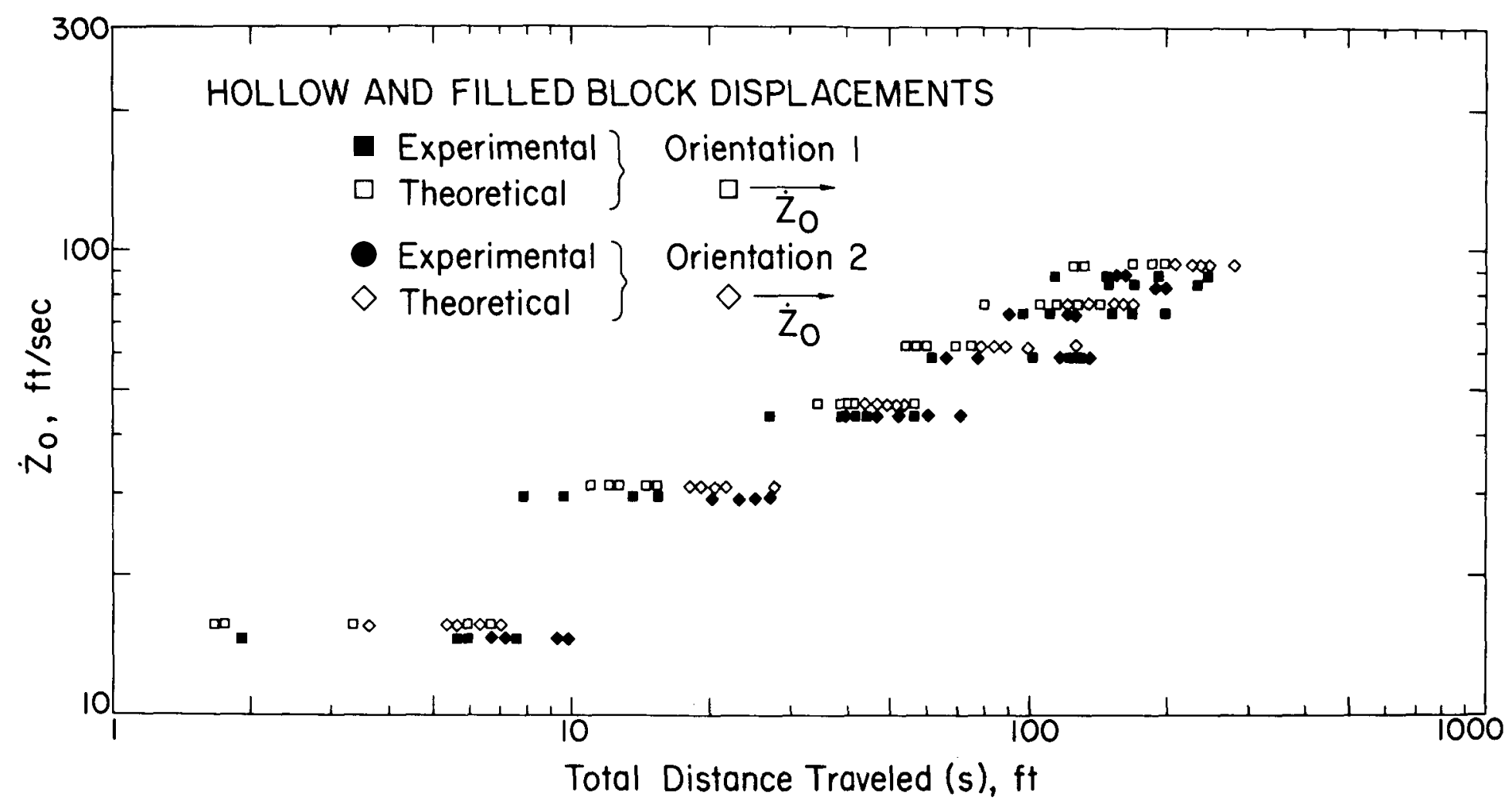

Figure 14. A comparison of experimental and theoretical data. Total distance traveled is plotted as a function of initial velocity for hollow and filled blocks dropped in the two indicated initial orientations. 
should at least be mentioned even though it is beyond the scope of this paper to discuss the damage to biological or physical targets that might result from these translational phenomena.

Of particular significance is the problem of secondary missiles, or blast-energized debris. These missiles may or may not represent a biological hazard depending, among other things, on the velocities, sizes, shapes, and materials involved. If the blast-wave parameters are known and if the missiles are relatively free to move, the translation model can be used to compute the time-displacement histories of the objects assuming they are in free air or bouncing along the ground. Additional assumptions are sometimes necessary depending on the circumstances of exposure. Appropriate approximations for predicting the time-displacement histories of fragments from concrete-block walls were discussed in this paper, and those for computing the motion of window-glass fragments were studied by Bowen et al. (1963).

One limitation of the present translation model is the assumption of unidirectional winds which produce only one-dimensional displacements. It has been shown that the model is reasonably adequate for computing displacement associated with near-classical blast waves in "clean" geometries (i.e., unperturbed radial winds), and although verification is not now available, it is presumed that model solutions for disturbed wave forms (precursor, for example) would be satisfactory provided appropriate parameters of the wave could be specified.

Other problems such as translation in shelters, in and behind buildings, and in forests, do not fall in the categories mentioned above. To study these thoroughly, it would be necessary to develop a threedimensional translation model and a three-dimensional decelerative tumbling model. Although some translation experiments have been conducted in shelters (White et al., 1957; Richmond et a1., 1959; Bowen et al., 1963) and the problems have been approached theoretically (Fletcher, 1965c), much more experimental and theoretical effort is needed in this field.

It has been shown that the translation of gravel placed in front of a wall at a distance greater than the structure's height or width was not greatly affected by the presence of the obstruction (Bowen et al., 1963). However, an adequate theory has not been developed for the translation of objects located relatively near a "large" obstruction when the blast wave is finite in duration, although a theory for flat-top blast waves has been reported (White et al., 1965; Fletcher, 1965c).

Another translational problem associated with surface bursts involves crater debris or ejecta. Because both earth and air motion accelerate the ejecta, the translation model cannot be used to predict velocities and displacements. However, ejecta velocities have been estimated from the distances to impact with, and without, the arrival times (Bowen et al., 1965). 


\section{SUMMARY}

A revised mathematical model of blast-induced translational effects was discussed which has two advantages over the earlier models: (1) arbitrary blast-wave forms can be used and (2) the effects of ground friction can be included if the translating object is tumbling over smooth flat ground. For relatively short-duration blast waves (such as those produced by $\mathrm{HE}$ ) the single most important blast-wave parameter needed to predict translation is the dynamic-pressure impulse.

Experiments involving the translational velocities of steel spheres were described, the results of which were used to estimate dynamicpressure impulse by two methods: the first was accomplished by means of the mathematical model and the second simplified technique required only a least-squares analysis of the experimental data. The experimental sphere velocities were compared to the velocities computed with the translation model using the blast waves predicted by various authors, and the discrepancies were discussed.

In order to understand the process of decelerative tumbling, a series of "calibration" experiments were performed in which concrete blocks, stones, and animals were dropped from a truck traveling at various speeds and the distances between bounces and the total displacements were measured. From these experiments an "average ground friction" term was derived and included in the translation model.

The model was tested using data obtained in experiments where dummies and goats were displaced by the winds from a 500-ton TNT detonation. The computed velocities and displacements were in reasonable agreement with the experimental results except in those cases where anomalous non-radial winds were present. The model could not be adequately tested for the latter cases since appropriate blast-wave parameters were not available.

In another experiment, the velocity distribution of the larger fragments from a concrete-block wall blown apart by the winds from an $11-k t$ nuclear shot was reconstructed from the measured displacements of the fragments and the "calibration" experiments. The geometric mean velocity of the fragments was shown to be in good agreement with the predicted velocity for a single loose block situated in free air.

A brief description was given of a mathematical model which was developed to study the mechanisms of decelerative tumbling for stones, blocks, and animals and to be able to extrapolate to greater velocities than have heretofore been obtained experimentally. The predictions of the model were shown to be in good agreement with the results of the "calibration" experiments for block translations. 


\section{REF ERENCES}

Anderson, R. S., F. W. Stemler and E. B. Rogers. 1961. Air Blast Studies with Animals II. Technical Report DASA-1193. Defense Atomic Support Agency.

Bowen, I. G., A. F. Strehler and M. B. Wetherbe. 1956. Distribution and Density of Missiles from Nuclear Explosions. USAEC Civil Effects Test Group WT-1168.

Bowen, I. G., R. W. Albright, E. R. Fletcher and C. S. White. 1961. A Model Designed to Predict the Motion of Objects Translated by Classical Blast Waves. Civil Effects Test Operations USAEC Report ECX-58.9.

Bowen, I. G., P. B. Woodworth, M. E. Franklin and C. S. White. 1962. Translational Effects of Air Blast from High Explosives. Proceedings of the Symposium on Effectiveness Analysis Techniques for Non-Nuclear Warheads Against Surface Targets. 1: M-M-61. U. S. Naval Weapons Laboratory. Also Technical Progress Report DASA-1336. Defense Atomic Support Agency.

Bowen, I. G., Mary E. Franklin, E. R. Fletcher and R. W. Albright. 1963. Secondary Missiles Generated by Nuclear Produced Blast Waves. USAEC Civil Effects Test Group Report WT-1468.

Bowen, I. G., E. R. Fletcher and R. F. Perret. 1965. Translation of Goats and Anthropomorphic Dummies by Blast Waves. Technical Report DASA-1656. Defense Atomic Support Agency. Also in Symposium Proceedings: Operation Snowball. 1: 454-481. Department of Defense.

Bowen, I. G. and E. R. Fletcher. Unpublished Experiments from Operation Blowdown in Australia in 1963.

Brode, H. L. 1957. A Calculation of the Blast Wave from a Spherical Charge of TNT. Research Memorandum-RM-1965. The Rand Corporation, 1700 Main Street, Santa Monica, California.

Dewey, J. M. 1964. The Air Velocity and Density in Blast Waves from TNT Explosions. Suffield Report 207. Defence Research Board, Department of National Defence, Suffield Experimental Station, Ralston, Alberta, Canada.

Fletcher, E. R., R. W. Albright, V. C. Goldizen and I. G. Bowen. 1961. Determinations of Aerodynamic Drag Parameters of Small Irregular Objects by Means of Drop Tests. Civil Effects Test Operations USAEC Report CEX-59. 14. 
Fletcher, E. R., I. G. Bowen and R. F. Perret. 1965a. Impact Velocities of Steel Spheres Translated by Air Blast. Technical Report DASA-1656. Defense Atomic Support Agency. Also in Symposium Proceedings; Operation SnowBall. 1: 454-481. Department of Defense.

Fletcher, E. R. 1965b. The Physics of Decelerative Tumbling. (in press). Presented at the Fifth Meeting of Panel N-1 (Biomedical), Sub-Group N, Tripartite Technical Cooperation Program.

Fletcher, E. R. 1965c. Translational Problems in Shelters. (in press). Presented at the Fifth Meeting of Panel N-1 (Biomedical), Sub-Group N, Tripartite Technical Cooperation Program.

Fletcher, E. R. Unpublished Studies on a Model Designed to Predict the Motion of Objects Translated by Arbitrary Blast Waves.

Glasstone, Samuel, ed., 1962. The Effects of Nuclear Weapons. Rev. Ed. U. S. Atomic Energy Commission.

Hoerner, Sighard. 1958. Fluid-Dynamic Drag. Sighard Hoerner, 148 Busteed Drive, Midland Park, New Jersey.

Keefer, J. 1965. Evaluation of New Air Blast Instruments. DASA Data Center Special Report 34-1. Department of Defense.

Mills, R. R., F. J. Fisch, B. W. Jezek and W. E. Baker. 1964. SelfConsistent Blast Wave Parameters. Technical Report DASA-1559. Defense Atomic Support Agency.

Minor, E. E. 1964. Letter Report of SnowBall Data. Terminal Ballistics Laboratory. Ballistics Research Laboratory.

Richmond, D. R., R. V. Taborelli, I. G. Bowen, T. L. Chiffelle, F. G. Hirsch, B. B. Longwell, J. G. Riley, C. S. White, F. Sherping, V. C. Goldizen, J. D. Ward, M. B. Wetherbe, V. R. Clare, M. L. Kuhn and R. T. Sanchez. 1959. Blast Biology - A Study of the Primary and Tertiary Effects of Blast in Open Underground Protective Shelters. USAEC Civil Effects Test Group Report WT-1467.

Taborelli, R. V., I. G. Bowen and E. R. Fletcher. 1959. Tertiary Effects of Blast Displacement. USAEC Civil Effects Test Group Report WT-1469.

White, C. S., T. L. Chiffelle, D. R. Richmond, W. H. Lockyear, I. G. Bowen, V. C. Goldizen, H. W. Merideth, D. E. Kilgore, B. B. Longwell, J. T. Parker, F. Sherping and M. E. Cribb. 1957. Biological Effects of Pressure Phenomena Occurring 
Inside Protective Shelters Following a Nuclear

Detonation. USAEC Civil Effects Test Group WT-1179.

White, Clayton S. I. Gerald Bowen and Donald R. Richmond. 1965.

Biological Tolerance to Air Blast and Related Biomedical

Criteria. Civil Effects Test Operations USAEC Report $\mathrm{CEX}-65.4$. 


\section{DISTRIBUTION}

\section{ARMY AGENCIES}

Chief of Research and Development, Life Sciences Division, Dept. of the Army, ATTN: CRDLS, Washington, D. C. 20310 (1 copy)

Chief of Research and Development, Dept. of the Army, ATTN: CRDNCB, Washington, D. C. $20310 \cdot(1$ copy)

Assistant Chief of Staff for Intelligence, Dept. of the Army, ATTN: DFISS, Washington, D. C. 20310 (1 copy)

Chief of Engineers, Department of the Army, ATTN: ENGTE-E, Washington, D. C. 20315 (1 copy)

Directorate of Transportation, U.S. Army Materiel Cmd., Washington, D. C. 20315 (1 copy)

Commanding General, Medical Research and Development Cmd., Dept. of the Army, ATTN: MEDDH-N, Main Navy Building, Washington, D. C. 20360 (2 copies)

Commanding General, Medical Research and Development Cmd., Dept. of the Army, ATTN: MEDPS-CS, Main Navy Bldg., Washington, D. C. 20360 (2 copies)

Commanding General, Medical Research and Development Command, Dept. of Army, ATTN: MEDDH-RS, Main Navy Bldg., Washington, D. C. 20360 (2 copies)

U.S. Army CDC Artillery Agency, Fort Sill, Oklahoma 73503 (1 copy)

President, Aviation Test Board, U.S. Army Aviation Center, Fort Rucker, Alabama 36362 (1 copy)

Assistant Chief of Staff for Force Development, Dept. of the Army, ATTN: Directorate of CBR and Nuclear Operations, Washington, D. C. 20310 (1 copy)

Commandant, U.S. Army C\&GS College, ATTN: Archives, Fort Leavenworth, Kansas 66027 (1 copy)

Commandant, U.S. Army Air Defense School, ATTN: Command \& Staff Dept., Fort Bliss, Texas 79906 (1 copy)

Commanding Officer, U.S. Army CDC Armor Agency, Fort Knox, Kentucky 40120 (1 copy)

Commanding Officer, U.S. Army CDC Artillery Agency, Fort Sill, Oklahoma 73503 (1 copy)

Commanding Officer, U.S. Army CDC Infantry Agency, Fort Benning, Georgia 31905 (1 copy)

Commanding Officer, U.S. Army CDC CBR Agency, Fort McClellan, Alabama 36205 (1 copy)

Commandant, U.S. Army CBR, Weapons School, Dugway Proving Ground, Dugway, Utah 84022 (1 copy)

Commanding General, Army Medical Service School, Brooke Army Medical Center, ATTN: DCCO, Fort Sam Houston, Texas 78234 (1 copy)

Commanding General, The Engineer Center, ATTN: Asst Cmdt Engineer School, Fort Belvoir, Virginia 22060 (1 copy)

Commanding General, 9th Hospital Center, ATTN: CO, U.S. Army Nuclear Medicine Research Det., Europe, APO New York 09180 (1 copy)

Commanding Officer, U.S. Army Chemical Research and Development Lab. , Edgewood Arsenal, Maryland 21040 (1 copy)

Commandant, Walter Reed Army Institute of Research, Walter Reed Army Medical Center, Washington, D. C. 20012 (5 copies)

Commanding General, U.S. Army Natick Laboratories, ATTN: Technical Library, Natick, Massachusetts 01760 (1 copy) 
Commanding Officer, U.S. Army, Combat Development Cmd., Institute of Nuclear Studies, Fort Bliss, Texas 79906 (1 copy)

Commanding General, U.S. Army Combat Development Cmd., ATTN: CDC CD-F, Fort Belvoir, Virginia 22060 (2 copies)

Commanding General, U.S. Army, Combat Development Command, ATTN: Combat Support Group, Fort Belvoir, Va 22060 (1 copy)

Commanding Officer, U.S. Army, Combat Development Cmd, Medical Service Agency, Fort Sam Houston, Texas 78234 (1 copy)

Commanding General, U.S. Army, Combat Development Cmd, Combat Arms Group, Fort Leavenworth, Kansas 66027 (1 copy)

Director Armed Forces Institute of Pathology, Walter Reed Army Medical Center, 62516 th Street, N. W. , Washington, D. C. 20012 (1 copy)

Director, Waterways Experiment Station, P. O. Box 631, ATTN: Library, Vicksburg, Mississippi 39180 (1 copy)

Director, U.S. Army Ballistic Research Laboratories, Aberdeen Proving Ground, Maryland 21005 ( 2 copies)

Redstone Scientific Info Center, U.S. Army Missile Cmd, ATTN: Chief, Document Section, Redstone Arsenal, Alabama 35808 (1 copy)

Commanding General, Army Materiel Command, ATTN: AMCRD-BN, Washington, D. C. 20315 (1 copy)

Commanding Officer, U.S. Army Nuclear Defense Laboratory, ATTN: Librarian, Edgewood Arsenal, Maryland 21040 (1 copy)

Commanding General, Army Materiel Command, ATTN: EOD Division, Washington, D. C. 20315 (1 copy)

Office of the Secretary of the Army, Assistant Director of OCD, ATTN: Research, Washington, D. C. 20310 (5 copies)

\section{NAVY AGENCIES}

Chief of Naval Operations, Navy Department, ATTN: OPO3EG, Washington, D. C. 20350 (1 copy)

Chief of Naval Operations, Navy Department, ATTN: OP-75, Washington, D. C. 20350 (1 copy)

Chief of Naval Operations, Navy Department, ATTN: OP-922G2, Washington, D. C. 20350 (1 copy)

Chief of Naval Personnel, Tech Library, Code 11B, Navy Department, Washington, D. C. 20370 (1 copy)

Chief of Naval Research, Navy Department, ATTN: Code 811, Washington, D. C. 20390 (1 copy)

Chief, Bureau of Medicine and Surgery, Navy Department, ATTN: Code 74, Washington, D. C. 20390 (2 copies)

Chief, Bureau of Medicine and Surgery, Navy Department, ATTN: Code 71, Washington, D. C. 20390 (1 copy)

Chief, NAVSHIPS, Navy Department, ATTN: Code 423, Washington, D. C. 20390 (1 copy)

Chief, NAVSHIPS, Navy Department, ATTN: Code 364, Washington, D. C. 20390 (1 copy)

Director, U.S. Naval Research Laboratory, Washington, D. C. 20390 (1 copy)

Commander, U.S. Naval Ordnance Laboratory, White Oak, Maryland 20910 (1 copy)

CO, U.S. Naval Mine Defense Laboratory, Panama City, Florida 32401 (1 copy)

CO, U.S. Naval Unit, U.S. Army Chemical School, Fort McClellan, Alabama 36205 (1 copy) 
Nuclear Medicine Division, School of Submarine Medicine, U. S. Naval Submarine Medical Center, Box 600, U.S. Naval Submarine Base, New London, Groton, Connecticut 06340 (1 copy)

CO, U.S. Naval Hospital, ATTN: Director, REEL, NNMC, Bethesda, Md. 20014 (1 copy)

CO and Director, U.S. NRDL, ATTN: Tech Info Div, San Francisco, California 94135 (4 copies)

CO, Nuclear Weapons Training Center, Atlantic, U.S. Naval Base, ATTN: Nuclear Warfare Department, Norfolk, Virginia 23511 (1 copy)

CO, Nuclear Weapons Training Center, Pacific, U.S. Naval Air Station, North Island, San Diego, California 92135 (1 copy)

CO, U.S. Naval Damage Control Training Center, Naval Base, ATTN: NBC Defense Course, Philadelphia, Pennsylvania 19112 (1 copy)

Superintendent, U.S. Naval Postgraduate School, Monterey, California 93940 (1 copy)

U. S. Naval Schools Command, T. I., NBC Defense Dept., Box 104, Bldg 194, ATTN: Tech Library, San Francisco, California 94130 (1 copy)

Commanding Officer, U.S. Naval Air Development Center, ATTN: NAS, Librarian, Johnsville, Pennsylvania 18974 (1 copy)

Officer in Charge, U.S. Naval Supply Research and Development Facility, Naval Supply Center, Bayonne, New Jersey 07002 (1 copy)

Commanding Officer, U.S. Naval Medical Research Institute, National Naval Medical Center, Technical Reference Library, Bethesda, Maryland 20014 (2 copies)

Commandant, U.S. Marine Corps, ATTN: Code A03H, Washington, D. C. 20380 (1 copy)

U. S. Naval School of Aviation Medicine, U.S. Naval Aviation Medical Center, ATTN: Director of Research, Pensacola, Florida 32508 (1 copy)

Commanding Officer, U.S. Naval Weapons Laboratory, Dahlgren, Virginia 22448 (1 copy) David Taylor Model Basin, Code 258, Washington, D. C. 20007 (2 copies)

Commander, Naval Facilities Engineering Command, Department of the Navy, Washington, D. C. 20390 (1 copy)

Commander, U.S. Naval Applied Science Laboratory (Code 900), Naval Base, Brooklyn, New York 11251 (1 copy)

U.S. Naval Ordnance Test Station, Code 4563, China Lake, California 93555 (2 copies)

\section{AIR FORCE AGENCIES}

HQ USAF (1 copy)

HQ USAF (AFMSPA) T-8, Wash DC 20333 (1 copy)

HQ USAF (AFMSR), T-8, Wash DC 20333 (1 copy)

HQ USAF, Chief of Operations and Analysis, Wash DC 20330 (1 copy)

HQ USAF (AFRSTA), Wash DC 20330 (1 copy)

HQ USAF (AFTAC), 6801 Telegraph Road, Alexandria, Va. 22310 (1 copy)

HQ USAF (AFRDD), Wash DC 20330 (1 copy)

\section{AIR FORCE MAJOR COMMANDS}

AFSC (SCS-7), Andrews AFB, Wash DC 20331 (1 copy)

AFSC (SCB), Andrews AFB, Wash DC 20331 (1 copy)

AFSC (SCTR), Andrews AFB, Wash DC 20331 (1 copy)

ADC, Asst for Atomic Energy, ADLDCA, Ent AFB, Colorado 80912 (1 copy)

AUL, Maxwell AFB, Alabama 36112 (1 copy)

SAC (OA), Offutt AFB, Nebraska 68113 (1 copy)

SAC (SUP), Offutt AFB, Nebraska 68113 (1 copy) 
TAC (OA), Langley AFB, Virginia 23365 (1 copy)

AU, Office of the Surgeon, Maxwell AFB, Alabama 36112 (1 copy)

ATC, Office of the Surgeon, Randolph AFB, Texas 78148 (1 copy)

\section{AFSC ORGANIZATIONS}

AFSC Scientific and Tech Liaison Office, RTD, ATTN: AFUPO, Los Angeles, California 90045 (1 copy)

HQ, RTD (RTTW), Bolling AFB, Wash DC 20332 (1 copy)

HQ, FTD (TDFBD), Wright-Patterson AFB, Ohio 45433 (1 copy)

HQ, BSD (BSR-1), Norton AFB, California 92409 (1 copy)

HQ, ASD (ASMM), Wright-Patterson AFB, Ohio 45433 (1 copy)

HQ, RTD(SEG/SENS), Wright-Patterson AFB, Ohio 45433 (1 copy)

AFAPL(APS), Wright-Patterson AFB, Ohio 45433 (1 copy)

AFAL(AVS), Wright-Patterson AFB, Ohio 45433 (1 copy)

AFML(MAS), Wright-Patterson AFB, Ohio 45433 (1 copy)

HQ SSD(SSTR), AFUPO 45, Los Angeles, California 90045 (1 copy)

RADC(EMEAM), Griffiss AFB, NY 13440 (1 copy)

AFWL(WLR), Kirtland AFB, New Mexico 87117 (1 copy)

AFRPL(RPPP), Edwards AFB, California 93523 (1 copy)

HQ ESD (ESLE), L. G. Hanscom Fld, Bedford, Mass. 01731 (1 copy)

HQ AMD (AMR), Brooks AFB Tex 78235 (1 copy)

HQ AMD (AMRB), Brooks AFB Tex 78235 (1 copy)

HQ AMD (AMRO), Brooks AFB Tex 78235 (1 copy)

AFSWC (SWLA), Kirtland AFB NMex 87117 (1 copy)

AFWL (WLIL), Kirtland AFB NMex 87117 (1 copy)

AFWL (WLRB), Kirtland AFB NMex 87117 (2 copies)

USAF SAM (SMB), Brooks AFB Tex 78235 (1 copy)

6570 AMRL, Wright-Patterson AFB, Ohio 45433 (2 copies)

6571 ARL, Holloman AFB NMex 88330 (1 copy)

\section{OTHER AIR FORCE AGENCIES}

AFCRL, ATTN: CRQST-2, L. G. Hanscom Fld, Bedford, Mass. 01731 (1 copy)

Director, USAF Project Rand, AF Liaison Officer, Rand Corp (Library), 1700 Main St. , Santa Monica, California 90401 (1 copy)

Medical Service School (Rad Branch), Sheppard AFB Tex 76311 (1 copy)

HQ OAR (RROS), 1400 Wilson Blvd, Arlington, Virginia 22209 (1 copy)

AFOSR (SRGL), 1400 Wilson Blvd, Arlington, Virginia 22209 (1 copy)

AFIT (Tech Library), Wright-Patterson AFB, Ohio 45433 (1 copy)

Air Force Western Test Range (WTOSM), Vandenberg AFB, California 93437 (1 copy)

\section{DEPARTMENT OF DEFENSE AGENCIES}

DDC, Cameron Station, Alexandria, Virginia 22314 (20 copies)

Director of Defense Research and Engineering, ATTN: Tech Library, Washington, D. C. 20301 (1 copy)

Director of Defense Research and Engineering, ATTN: Chief, Medical Services Division, Office of Science, Washington, D. C. 20301 (1 copy)

Director, Defense Atomic Support Agency, ATTN: Document Library, Washington, D. C. 20301 (3 copies) 
Director, Defense Atomic Support Agency, ATTN: STMD (For TTCP), Washington, D. C. 20301 (12 copies)

Commander, Test Command, Defense Atomic Support Agency, Sandia Base, Albuquerque, New Mexico 87115 (1 copy)

Commander, Field Command, Defense Atomic Support Agency, Sandia Base, ATTN: Surgeon, Albuquerque, New Mexico 87115 (1 copy)

Commander, Field Command, Defense Atomic Support Agency, ATTN: FCTG, Albuquerque, New Mexico 87115 (1 copy)

Director, Armed Forces Radiobiology Research Institute, National Naval Medical Center, Bethesda, Maryland 20014 (2 copies)

Director, Weapons Systems Evaluation Group, Washington, D. C. 20305 (1 copy)

U.S. Documents Officer, Office of the United States National Military RepresentativeSHAPE, APO, New York, New York 09055 (1 copy)

Director, Armed Forces Institute of Pathology, Walter Reed Army Medical Center, Washington, D. C. 20012 (1 copy)

Director, ARPA, DOD, ATTN: Tech Info Officer, the Pentagon, Washington, D. C. 20301 (1 copy)

Director, DIA, ATTN: DIAAP-IKZ, Washington, D.C. 20301 (1 copy)

\section{OTHER FEDERAL AGENCIES}

Atomic Energy Commission, ATTN: Asst. Director for Medicine \& Health Research, DBM, Washington, D. C. 20545 (1 copy)

Atomic Energy Commission, Civil Effects Branch, Div of Biology and Medicine, Washington, D. C. 20545 (150 copies)

Atomic Energy Commission, Div of Technical Information Extension, P. O. Box 62, Oak Ridge, Tenn. 37830 (300 copies)

Director, National Aeronautics \& Space Admin., Washington, D. C. 20546 (1 copy)

National Aeronautics and Space Admin., ATTN: Director, Life Sciences Program, Washington, D. C. 20546 ( 1 copy)

National Library of Medicine, Accessions Branch, 8600 Wisconsin Ave., Bethesda, Maryland 20014 (1 copy)

Federal Air Surgeon, (AM-1) HQ Federal Aviation Agency, 800 Independence Ave., S. W. , Washington, D. C. 20553 (1 copy)

Public Health Service, 4th and Jefferson Drive, S. W., Washington, D. C. 20201 (1 copy)

Public Health Service, Southwest Radiological Health Lab., ATTN: Tech Library, P. O. Box 684, Las Vegas, Nevada 89101 (1 copy)

USPHS, Research Branch, Division of Radiological Health, 1901 Chapman Av., Rockville, Md. 20853 (1 copy)

USPHS, S. E. Radiobiology Health Laboratory, PO Box 61, Montgomery, Alabama 36101 (1 copy)

Lawerence Radiation Lab., U. of Calif., P. O. Box 808, ATTN: Information Integration Group, Livermore, California 94550 (1 copy)

Argonne National Laboratory, 9700 South Cass Ave., ATTN: Medical Div., Argonne, Illinois 60440 (1 copy)

Batelle N.W. Laboratory, P. O. Box 999, ATTN: Dr. Bair, Rickland, Washington 99352 (1 copy)

Brookhaven National Laboratory, Tech Information Div., Documents Group, Upton, New York 14100 (1 copy)

Los Alamos Scientific Laboratory, ATTN: Biomedical Research Group, P. O. Box 1663, Los Alamos, New Mexico 87544 (1 copy) 
Lawrence Radiation Laboratory, U. of California, P. O. Box 808, ATTN: Biomedical Research Div., Livermore, California 94550 (1 copy)

\section{NON FEDERAL AGENCIES}

National Academy of Sciences, ATTN: Richard Park, 2101 Constitution Ave., Washington, D. C. 20418 (5 copies)

Eric H. Wang Civil Engineering Research Facility, Box 188, University Station, U. of New Mexico, Albuquerque, New Mexico 87106 (1 copy)

Southwest Research Institute, ATTN: Technical Library, 8500 Culebra Road, San Antonio, Texas 78228 (1 copy)

Medical College of So. Carolina, Dept of Surgery, ATTN: Dr. M. S. Rittenbury, 55 Doughty St. , Charleston, So. Carolina 29403 (1 copy)

Cincinnati General Hospital, Radioisotope Lab., ATTN: Dr. E. L. Saenger, Cincinnati, Ohio 45229 (1 copy)

New York State Veterinary College, Cornell U., Dept. of Physical Biology, ATTN: Dr. Comar, Ithaca, New York 14850 (1 copy)

Lovelace Foundation for Medical Education \& Research, 5200 Gibson Blvd., S. E. , ATTN: Dr. C. S. White, Albuquerque, New Mexico 87108 (50 copies)

The Rand Corporation, 1700 Main St., Santa Monica, Calif. 90401 (1 copy)

U. of Rochester, School of Medicine \& Dentistry, Dept of Radiation Biology, P. O. Box 287, Station 3, Rochester, New York 14620 (1 copy)

U. of Rochester, P. O. Box 287, Station 3, ATTN: Atomic Energy Project Library, Rochester, New York 14620 (1 copy)

U. of New Mexico, ATTN: Library, Albuquerque, New Mexico 87106 (1 copy)

U. of Pennsylvania Medical School, Medical Library, ATTN: Librarian for Blast Biology, Philadelphia, Penn. 19104 (1 copy)

San Francisco State College, 1600 Holloway Ave., ATTN: Dr. Curtis Newcombe, San Francisco, Calif 94132 (1 copy)

Baylor University, ATTN: Document Library, 5th and Speight, Waco, Texas 76703 (1 copy)

University of California, ATTN: Director Radiobiology Lab., Davis, California 95616 (1 copy)

Laboratory of Nuclear Medicine \& Radiation Biology School of Medicine, U. of Calif. , ATTN: Library, 900 Veteran Ave., Los Angeles, Calif 90024 (1 copy)

Colorado State University, ATTN: Dir Collaborative Radiological Health Laboratory, Ft. Collins, Colo 80521 (1 copy)

Mass Institute of Technology, ATTN: MIT Library, Cambridge, Mass 02139 (1 copy)

Polaroid Corp, ATTN: Tech Library, 119 Windsor St., Cambridge, Mass 02139 (1 copy)

Medical College of Virginia, ATTN: Dept of Biophysics, 523 N. 12th St. , Richmond, Virginia 23219 (1 copy)

Sandia Corporation, P. O. Box 5800, ATTN: Dir of Research, Albuquerque, New Mexico 87115 (2 copies) 
Security Classification

\section{DOCUMENT CONTROL DATA - R\&D}

(Security claseiflcation of title, body of abstract and indexind annotation must be ontered when the overall report is classified)

1. ORIGINATING ACTIVITY (Corporate author)

Lovelace Foundation for Medical Education \& Research

Albuquerque, New Mexico 87108

3. REPORT TITLE

Blast Induced Translational Effects

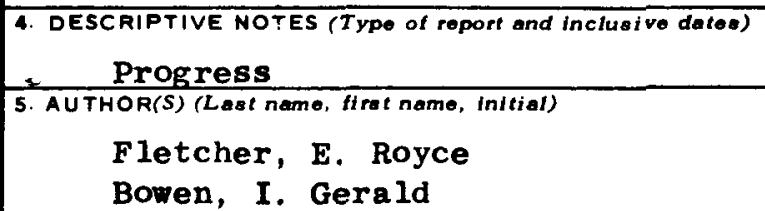

\begin{tabular}{|c|c|c|}
\hline $\begin{array}{l}\text { 6. REPORT DATE } \\
\text { November } 1966\end{array}$ & $\begin{array}{l}\text { 7A. TOTAL NO. OF PAGES } \\
38\end{array}$ & $\begin{array}{c}\text { 7b. NO. OF REFS } \\
24\end{array}$ \\
\hline $\begin{array}{l}\text { BA. CONTRACT ORGRANT NO. } \\
\text { DA-49-146-XZ-372 } \\
\text { b. PROJECT NO. } \\
03.012\end{array}$ & $\begin{array}{r}\text { 9. ORIGINATOR'S REPORT } \\
\text { DASA- } 1859\end{array}$ & BER(S) \\
\hline c. & 9b. OHHER REPORT NO(S) & other numbors chat may be aesiened \\
\hline
\end{tabular}

Distribution of this report is unlimited.

11. SUPPL EMEN TARY NOTES 12. SPONSORING MILITARY ACTIVITY

DASA

13. ABSTRACT

A mathematical model was developed to predict the time displacement histories of objects translated by the blast winds from conventional or nuclear explosions; these predictions were then compared to actual experiments. The objects studied varied in size from $139 \mathrm{mg}$ spheres to man and were all assumed to be free to move over a smooth horizontal surface. The effects of ground friction* could either be included or neglected, but when they were considered the ground friction eventually brought the objects to rest after the winds had passed. The values of ground friction used were determined experimentally and were found to be functions of the velocity and mass of the object being displaced.

The translational model was general enough for etther classical or nonclassical blast waves to be considered. Results for a chemical explosion were obtained by using both the computed blast waves of varlous authors and the experimentally determined blast waves. These predicted results were compared with each other as well as with experimental data obtained with steel spheres. The model was used to determine dynamicpressure impulses necessary to explain the measured sphere velocities at three ranges from ground zero.

Another mathematical model was briefly described which was developed to compute the detalled two-dimentional trajectories of objects as they roll, slide, and bounce along the ground. The model closely predicted the measured distances

Continued 


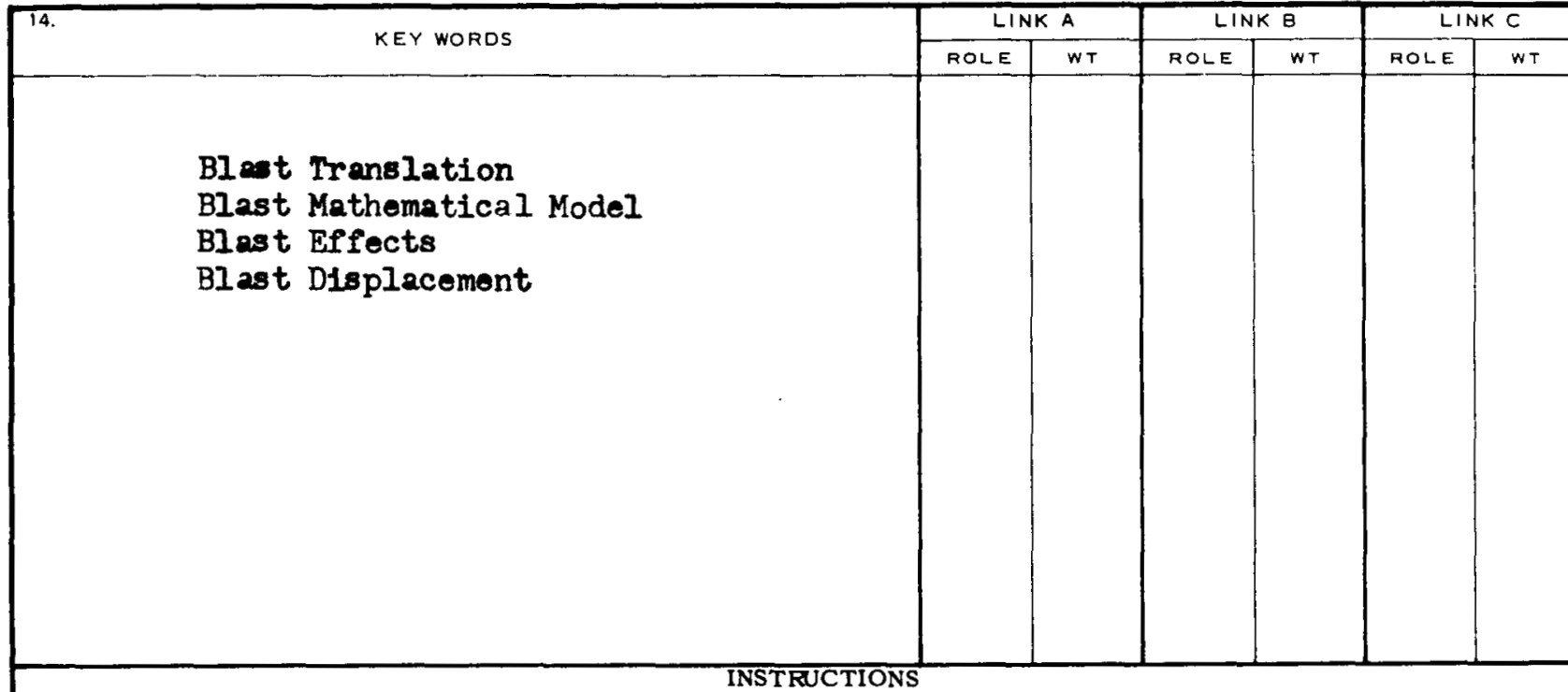

1. ORIGINATING ACTIVITY: Enter the name and address of the contractor, subcontractor, grantee, Department of Defense activity or other organization (comorate author) issuing the report.

2a. REPORT SECURTY CLASSIFICATION: Enter the overall security classification of the report. Indicate whether "Restricted Data" is included Marking is to be in accordance with appropriate security regulations.

2b. GROUP: Automatic downgrading is specified in DoD Directive 5200.10 and Armed Forces Industrial Manual. Enter the group number. Aiso, when applicable, show that optional markings have been used for Group 3 and Group 4 as authorized.

3. REPORT TITLE: Enter the complete report title in all capital letters. Titles in all cases should be unclassified. If a meaningful title cannot be selected without classification, show title classification in all capitals in parenthesis immediately following the title.

4. DESCRIPTIVE NOTES: If appropriate, enter the type of report, e.g., interim, progress, summary, annual, or final. Give the inclusive dates when a specific reporting period is covered.

5. AUTHOR(S): Enter the name(s) of author(s) as shown on or in the report. Enter last name, first name, middle initial. If military, show rank and branch of service. The name of the principal author is an absolute minimum requirement.

6. REPORT DATE: Enter the date of the report as day, month, year; or month, year. If more than one date appears on the report, use date of publication.

7 a. TOTAL NUMBER OF PAGES: The total page count should follow normal pagination procedures, i. e., enter the number of pages containing information.

7b. NUMBER OF REFERENCES: Enter the total number of references cited in the report.

8a. CON'TRACT OR GRANT NUMBER: If appropriate, enter the applicable number of the contract or grant under which the report was written

$8 b, 8 c, 8$ 8d. PROJECT NUMBER: Enter the appropriate military department identification, such as project number, subproject number, system numbers, task number, etc.

9a. ORIGINATOR'S REPORT NUMBER(S): Enter the official report number by which the document will be ident ified and controlled by the originating activity. This number must be unique to this report.

9b. OTHER REPORT NUMBER(S): If the report has been assigned any other report numbers (either by the originator or by the sponsor), also enter this number(s).
10. AVAIL ABILITY/LIMITATION NOTICES: Enter any $1 \mathrm{im-}$ itations on further dissemination of the report, other than those imposed by security classification, using standard statements such as:

(1) "Qualified requesters may obtain copies of this report from DDC."

(2) "Foreign announcement and dissemination of this report by DDC is not authorized."

(3) "U. S. Government agencies may obtain copies of this report directly from DDC. Other qualified DDC users shall request through

(4) "U. S. military agencies may obtain coples of this report directly from DDC Other qualified users shall request through

$\therefore$

(5) "All distribution of this report is controlled Qualified DDC users shall request through ,

If the report has been furnished to the Office of Technical Services, Department of Commerce, for sale to the public, indicate this fact and enter the price, if known.

11. SUPPLEMENTARY NOTES: Use for additional explanatory notes.

12. SPONSORING MILITARY ACTIVITY: Ent er the name of the departmental project office or laboratory sponsoring (pay ing $f \circ r)$ the research and development. Include address.

13. ABSTRACT: Enter an abstract giving a brief and factual summary of the document indicative of the report, even though it may also appear elsewhere in the body of the technical report. If additional space is required, a continuation sheet shall be attached.

It is highly desirable that the abstract of classified reports be unclassified. Each paragraph of the abstract shall end with an indication of the military security classification of the information in the paragraph, represented as (TS), (S), (C), ot (U)

There is no limitation on the length of the abstract. However, the suggested length is from 150 to 225 words.

14. KEY WORDS: Key words are technically meaningful terms or short phrases that characterize a report and may be used as index entries for cataloging the report. Key words must be selected so that no security classification is required. Idenfiers, such as equipment model designation, trade name, mili tary project code name, geopraphic location, may be used as key words but will be followed by an indication of technical context. The assignment of links, rules, and weights is optional. 
DD Form 1473 Continued

DASA - 1859

between bounces and the total displacements of concrete blocks and large stones and thus helped to explain the mechanisms of tumbling by which an irregular object may become airborne during both the accelerative and the decelerative phases of displacement.

* Ground friction is used here to designate the process of energy dissipation by sliding, rolling, and impacting along the ground. 